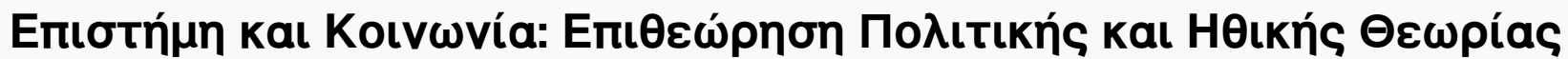

Tó 21 (2009)

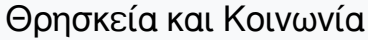

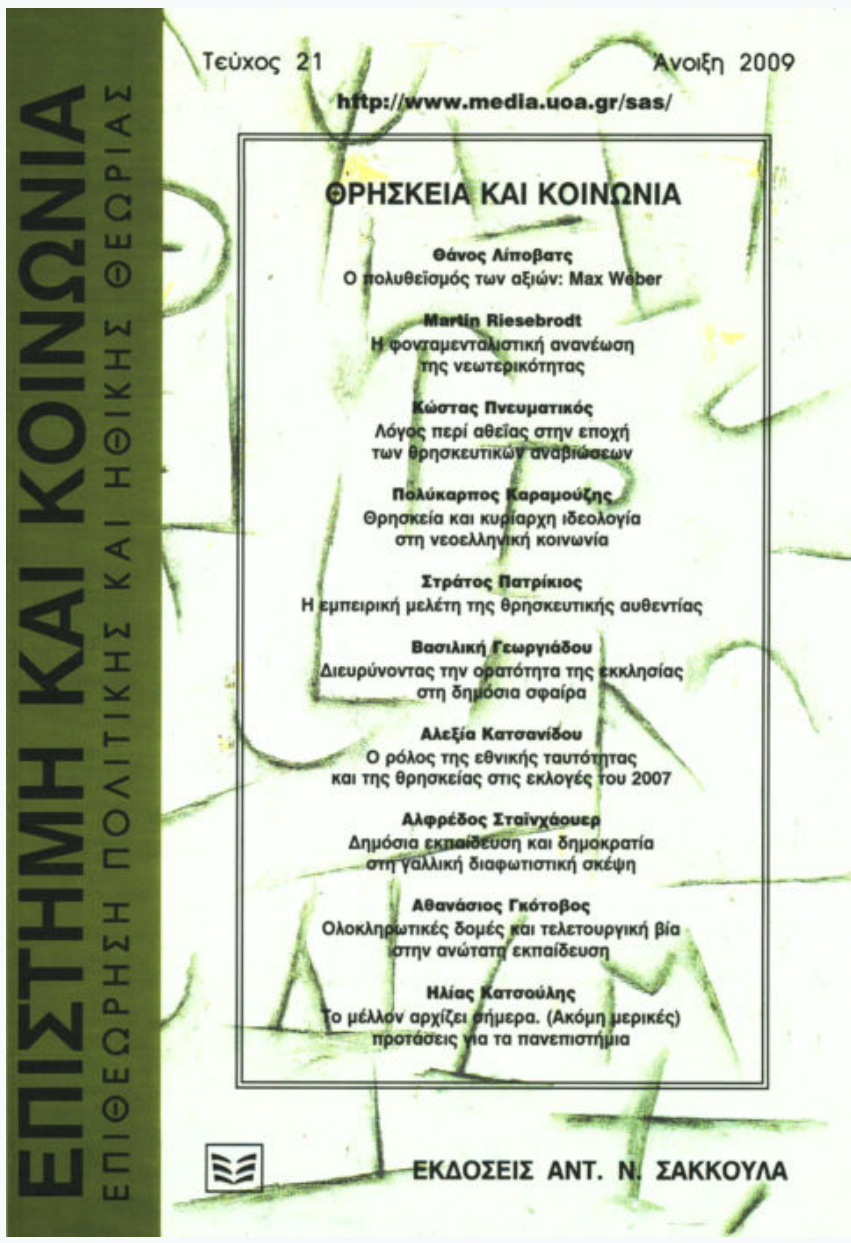

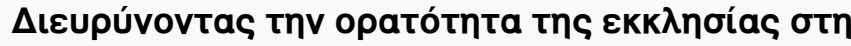

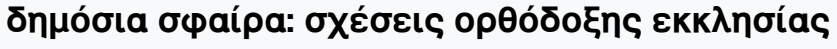

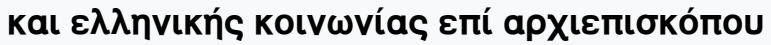
Xpıбтóठоuגou

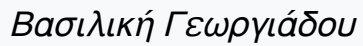

doi: $\underline{10.12681 / \text { sas. } 455}$

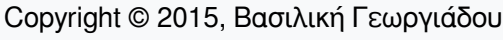

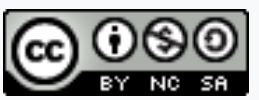

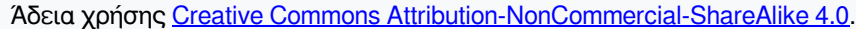

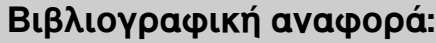

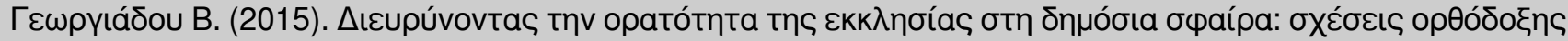

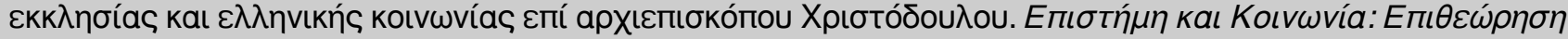

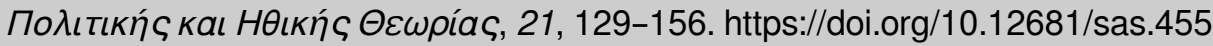




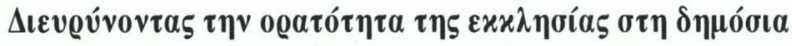

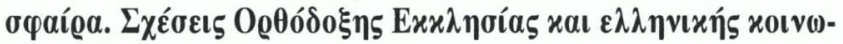

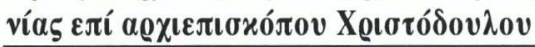

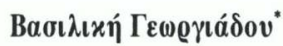

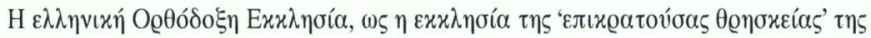

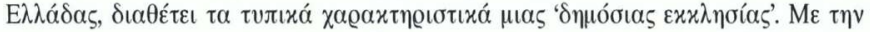

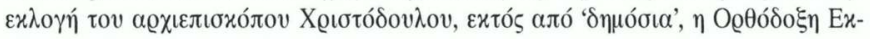

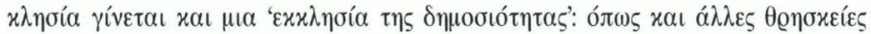

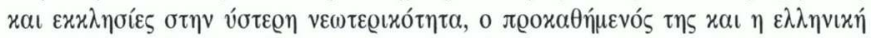

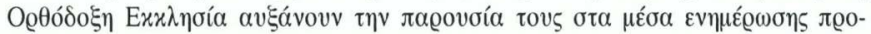

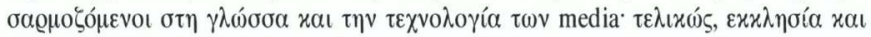

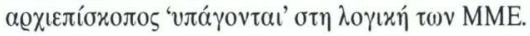

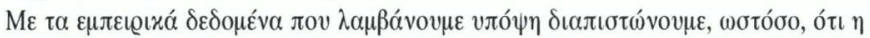

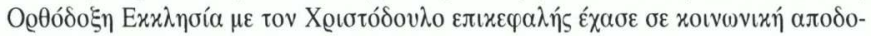

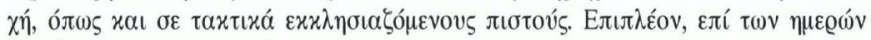

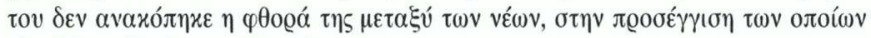

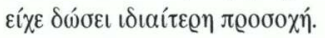

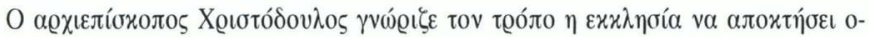

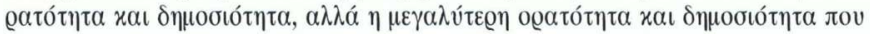

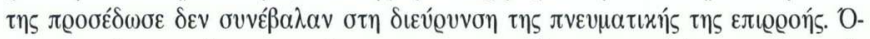

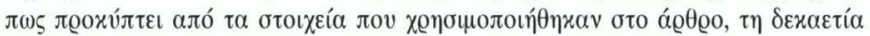

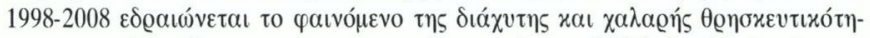

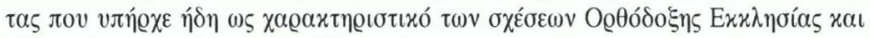

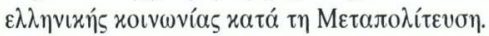

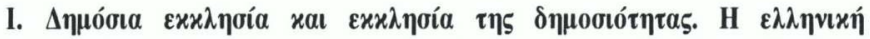

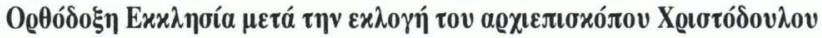

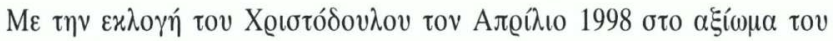

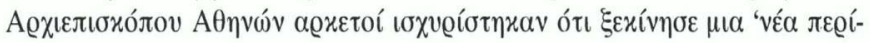

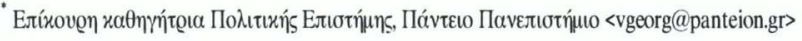




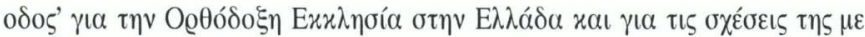

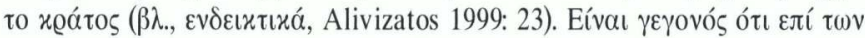

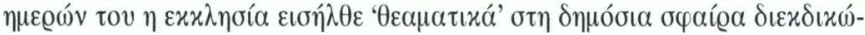

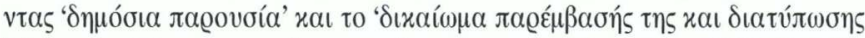

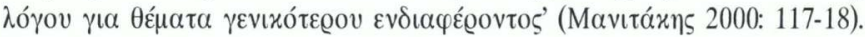

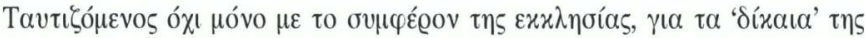

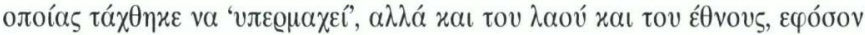

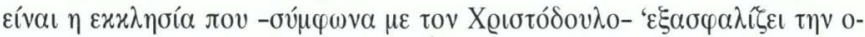

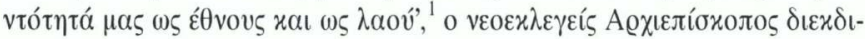

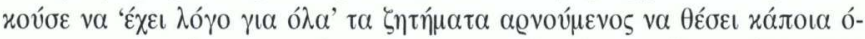

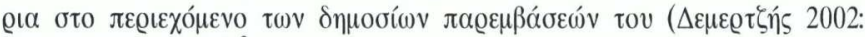
154-55, 2001: 87, 89). ${ }^{2}$

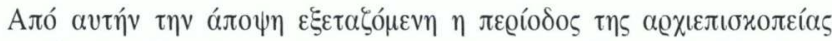

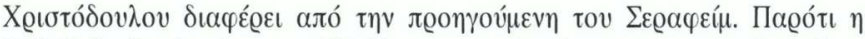

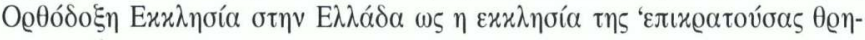

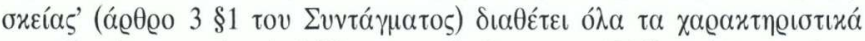

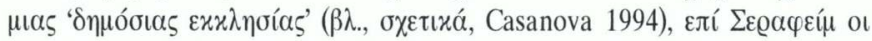

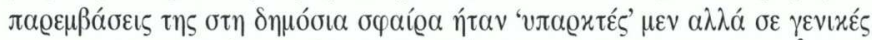

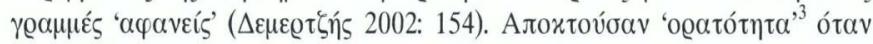

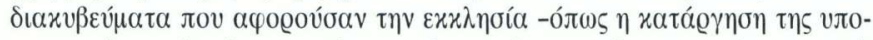

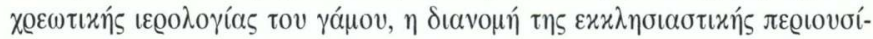

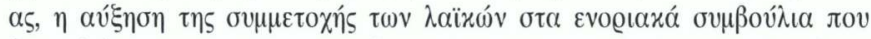

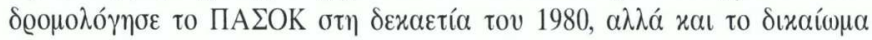

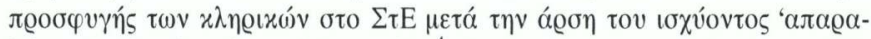

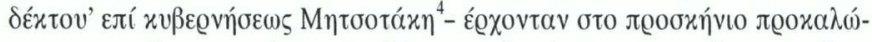

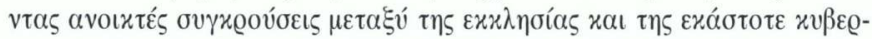

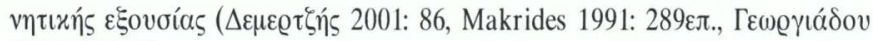
1996: 260-63).

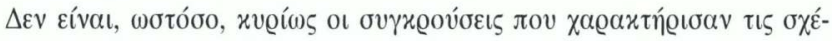

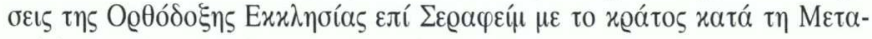

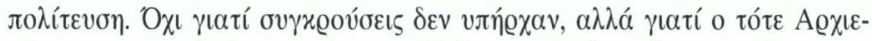

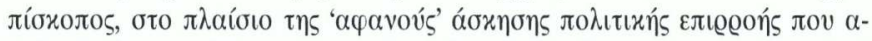

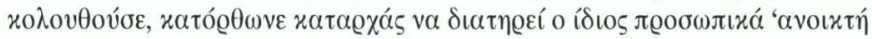

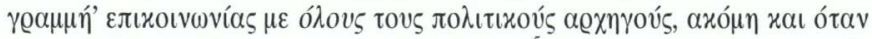

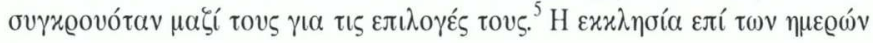




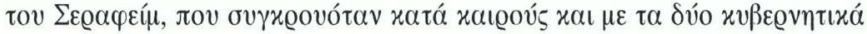

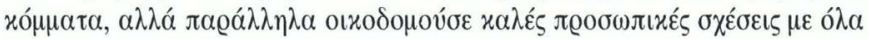

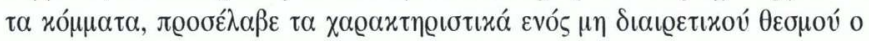

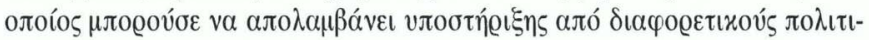

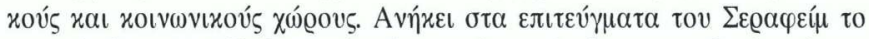

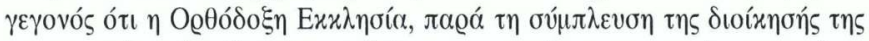

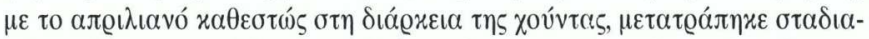

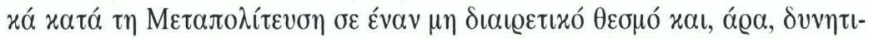

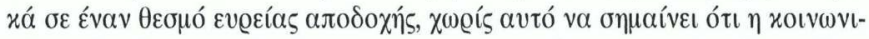

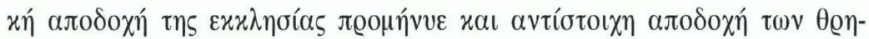

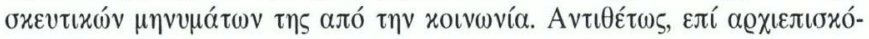

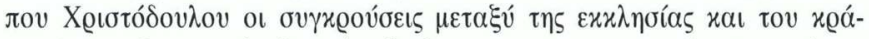

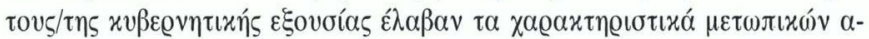

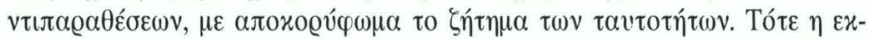

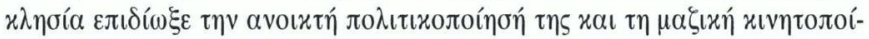

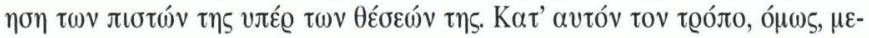

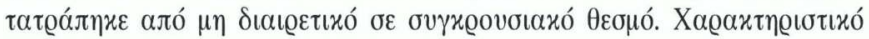

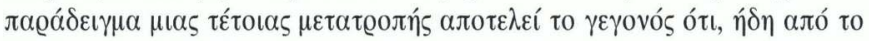

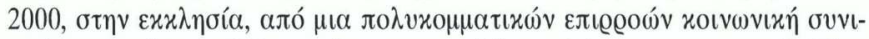

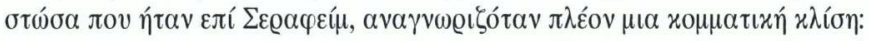

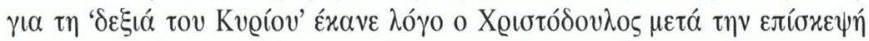

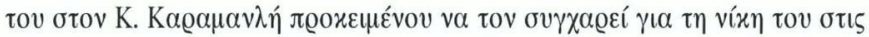

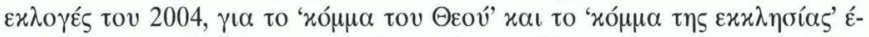

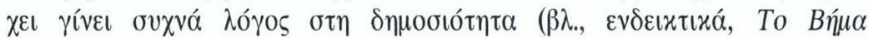

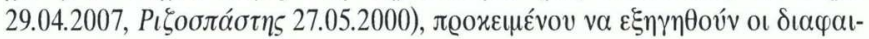
vó

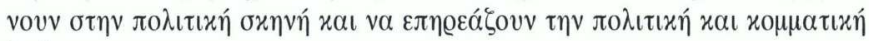
$\xi \omega \eta$.

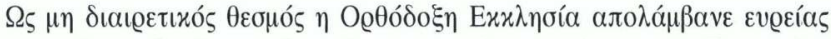

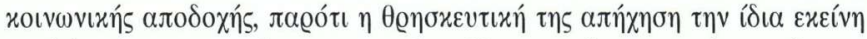

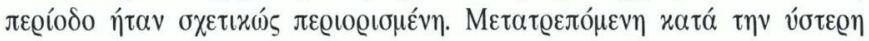

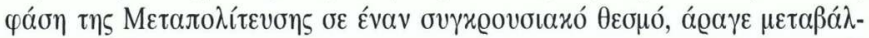

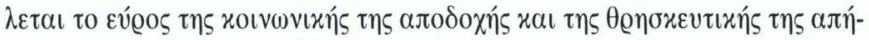

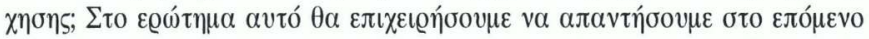

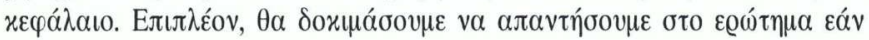




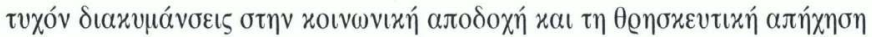

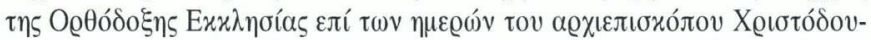

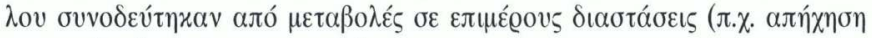

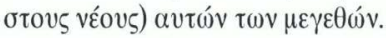

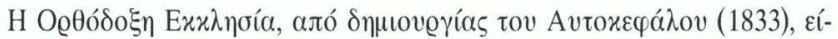

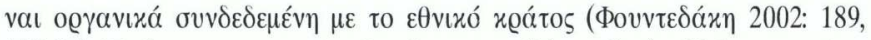

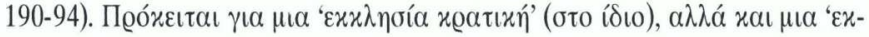

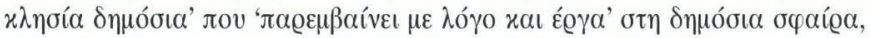

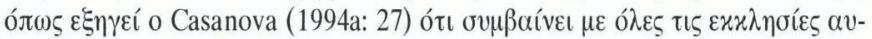

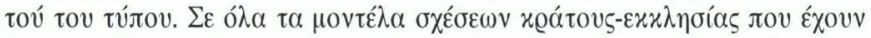

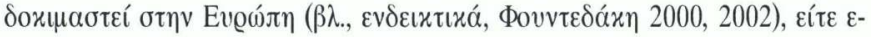

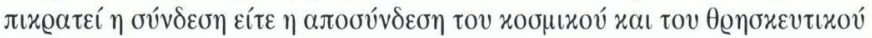

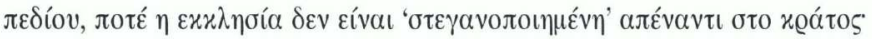

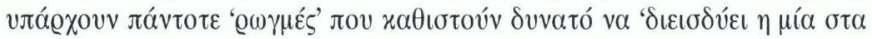

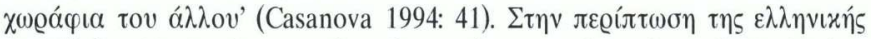

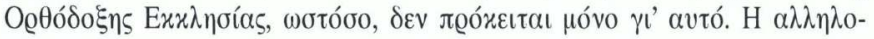

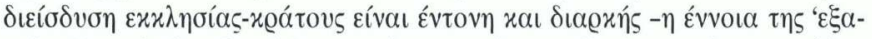

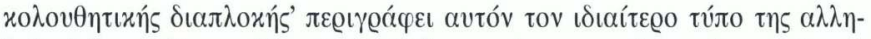

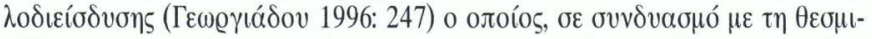

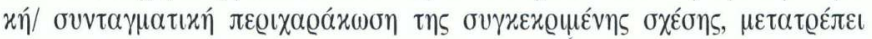

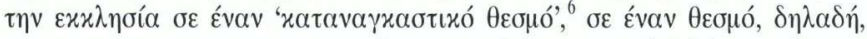

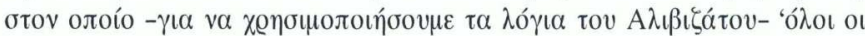

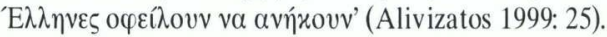

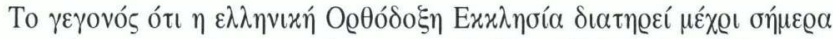

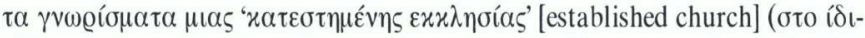

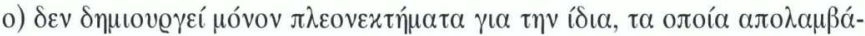

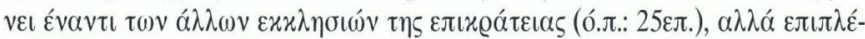

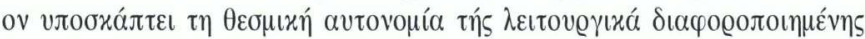

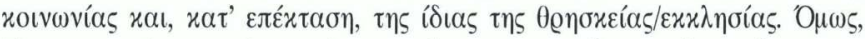

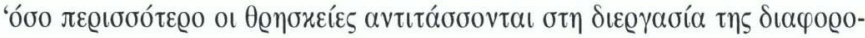

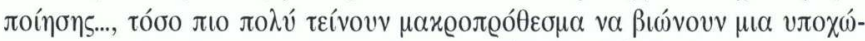

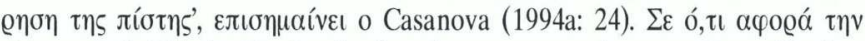

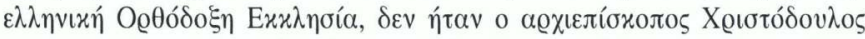

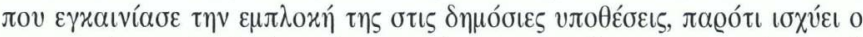

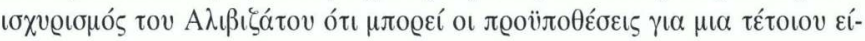




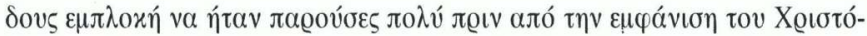

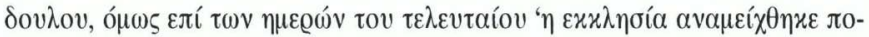

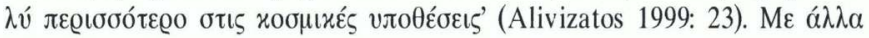

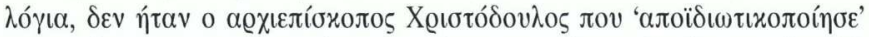

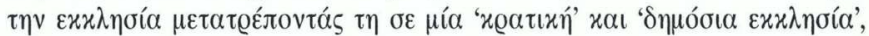

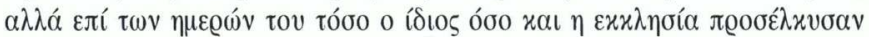

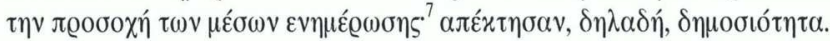

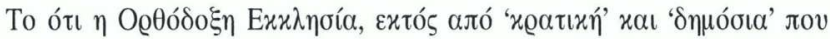

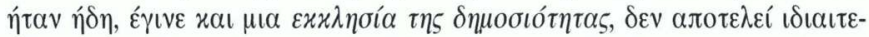

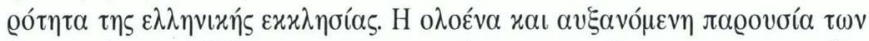

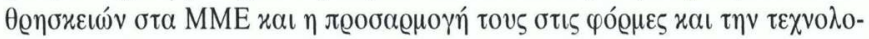

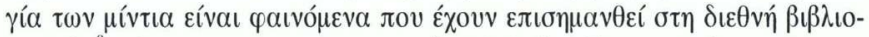

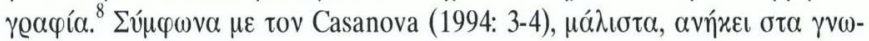

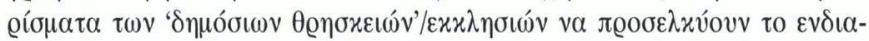

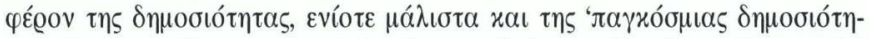

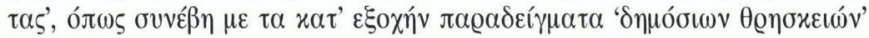

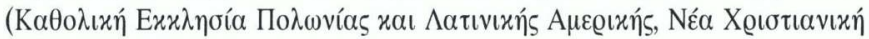

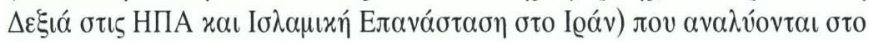

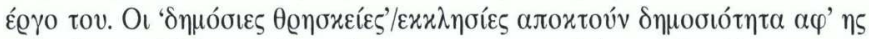

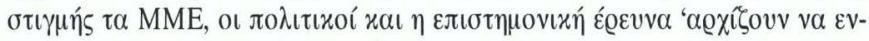

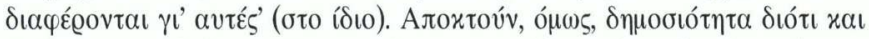

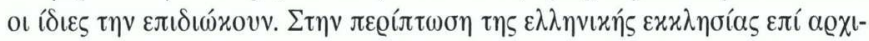

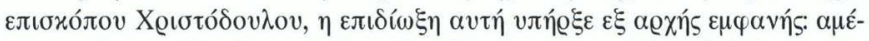

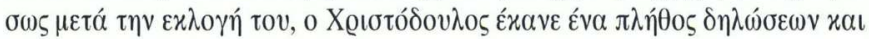

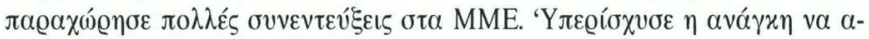

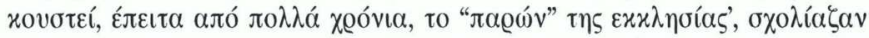

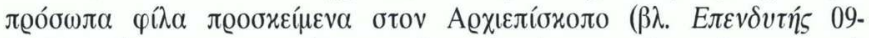

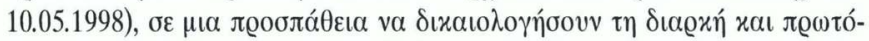

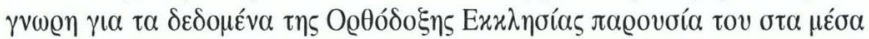

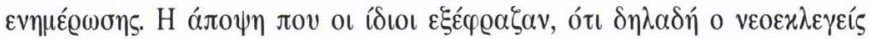

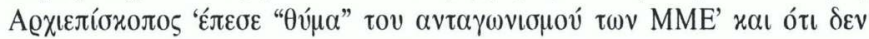

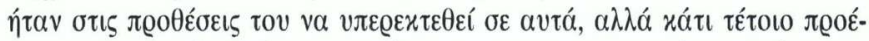

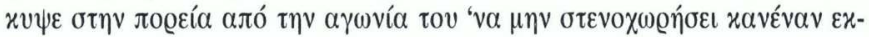

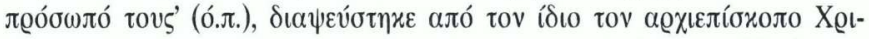

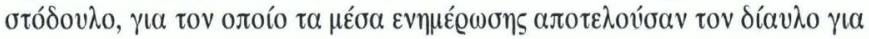




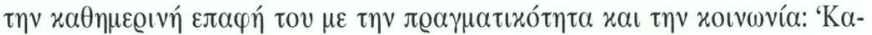

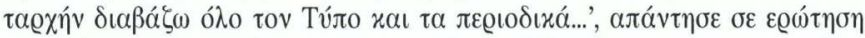

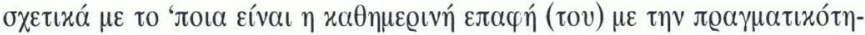

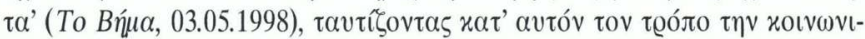

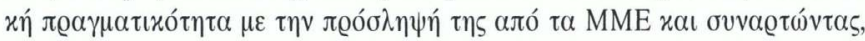

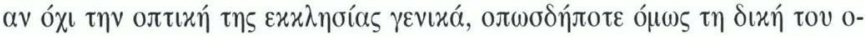

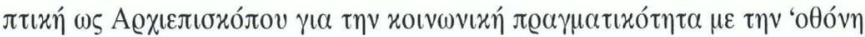

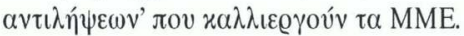

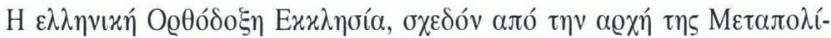

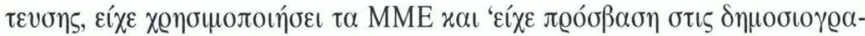

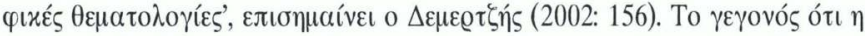

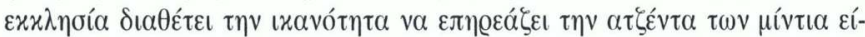

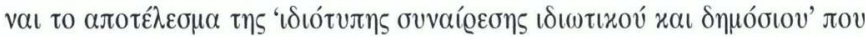

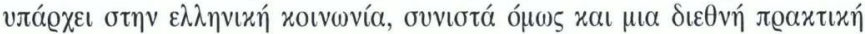

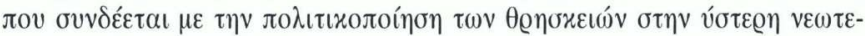

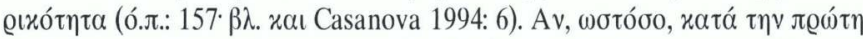

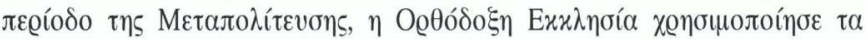

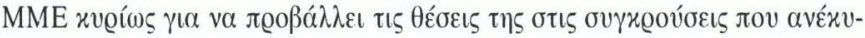

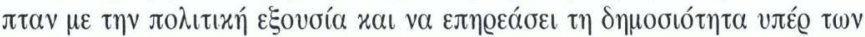

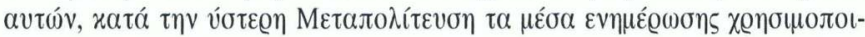

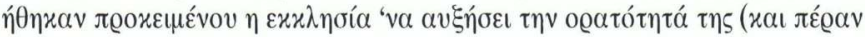

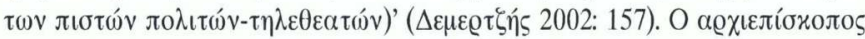

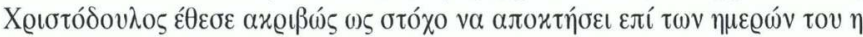

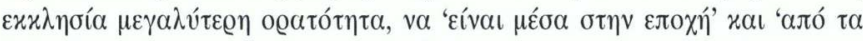

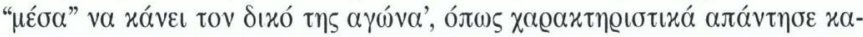

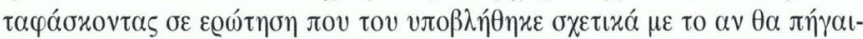

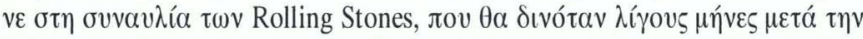

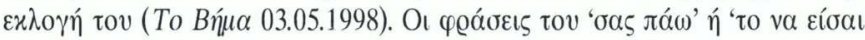

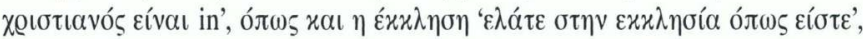

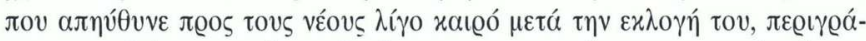

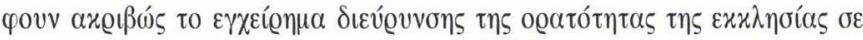

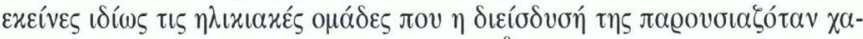

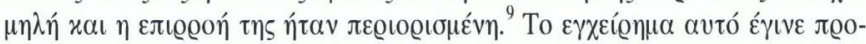

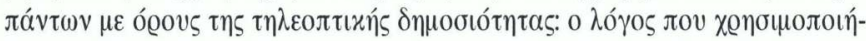

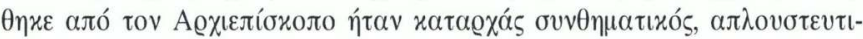




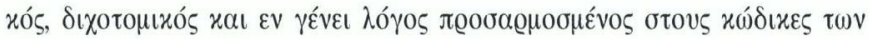

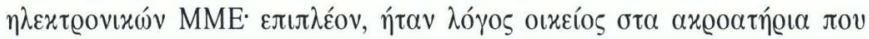

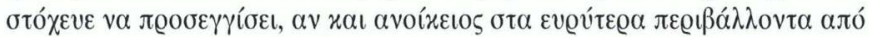

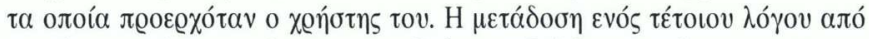

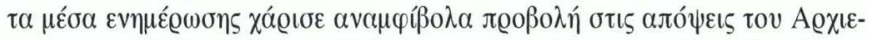

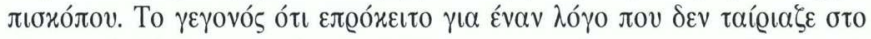

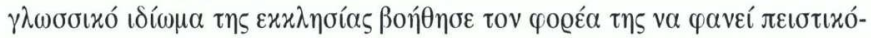

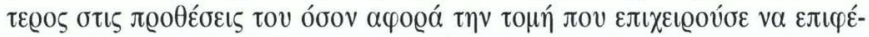

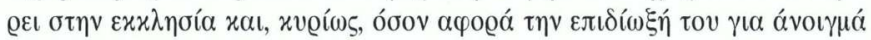

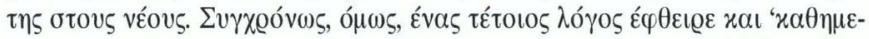

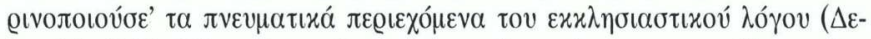

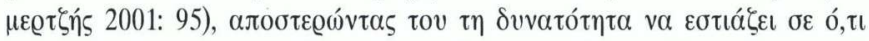

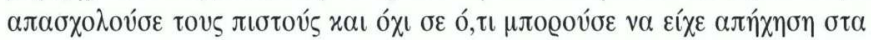
$\mu i ́ v \tau i \alpha$.

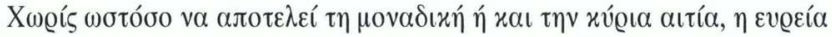

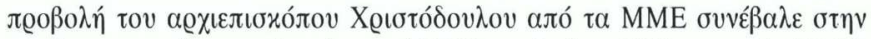

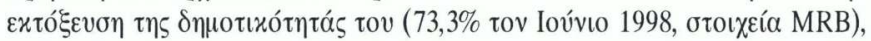

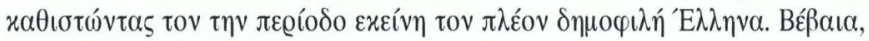

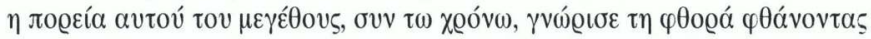

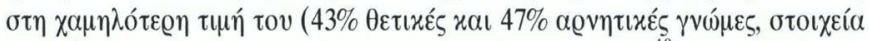

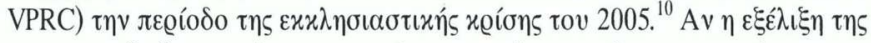

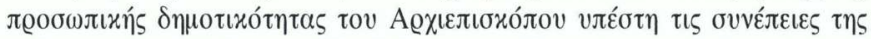

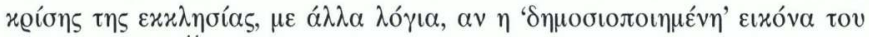

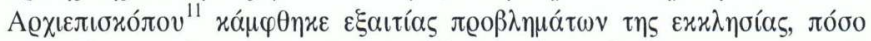

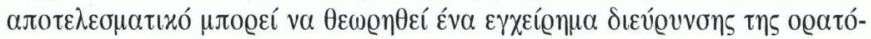

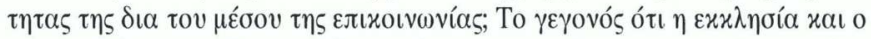

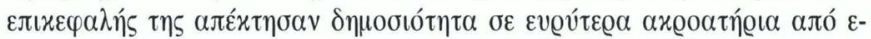

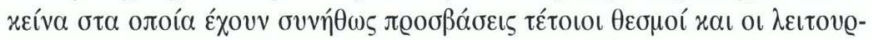

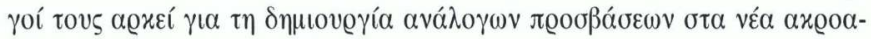

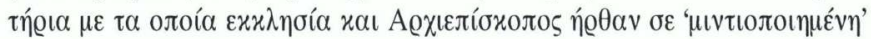

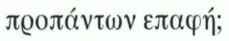

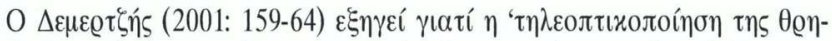

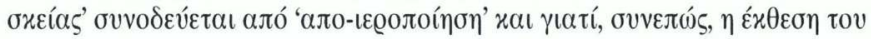

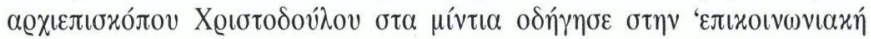

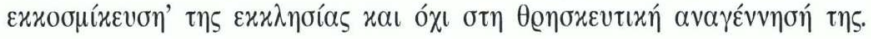




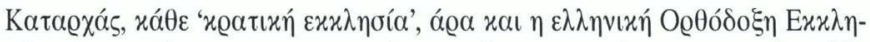

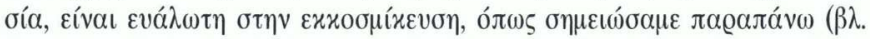

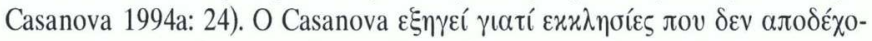

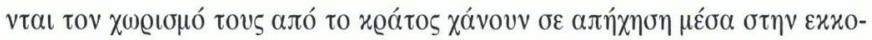

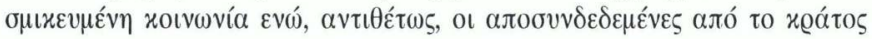

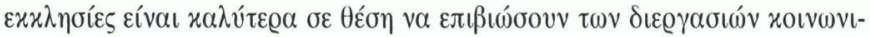

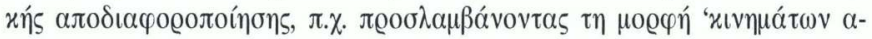

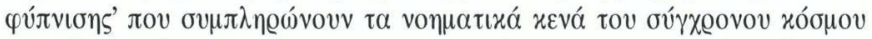

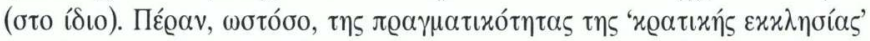

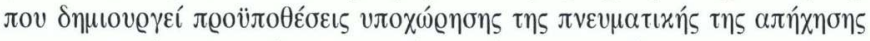

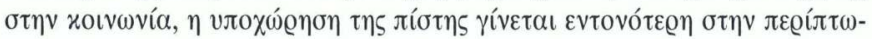

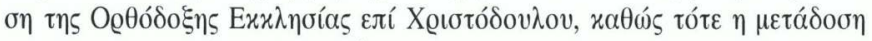

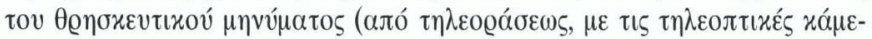

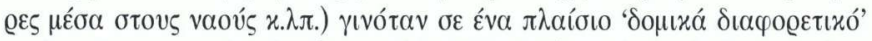

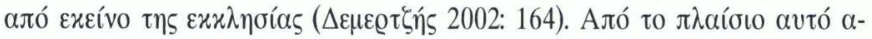

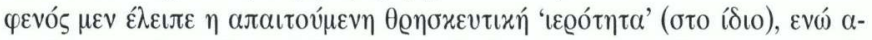

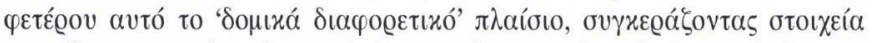

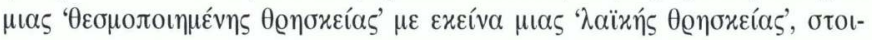

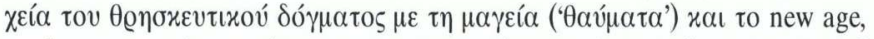

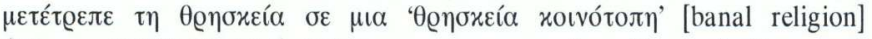

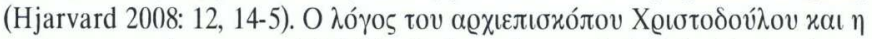

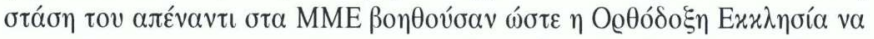

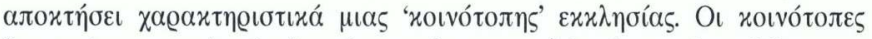

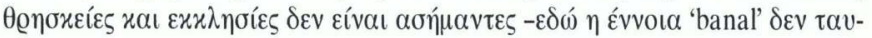

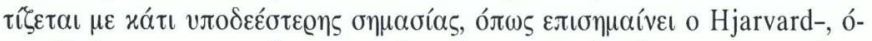

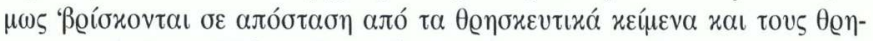

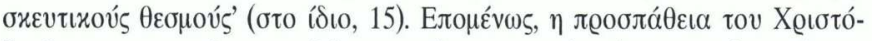

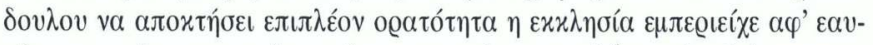

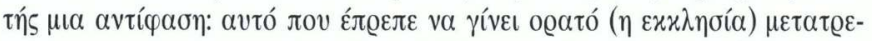

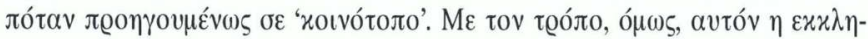

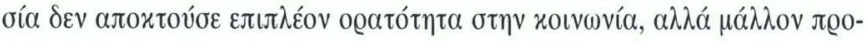

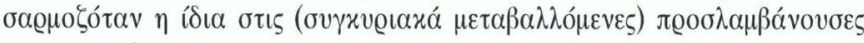

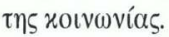




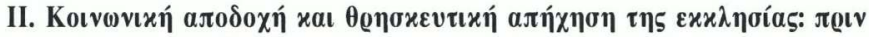

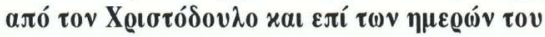

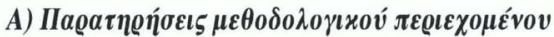

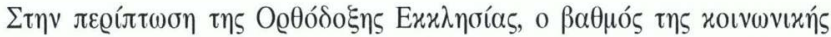

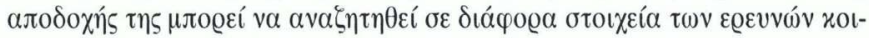

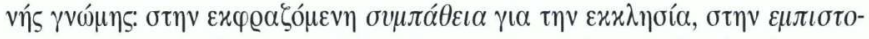

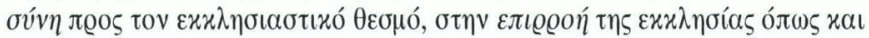

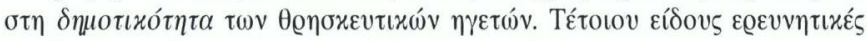

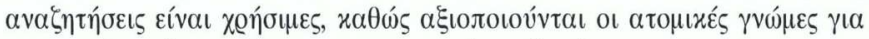

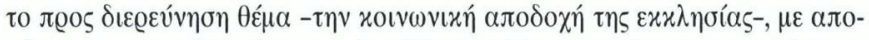

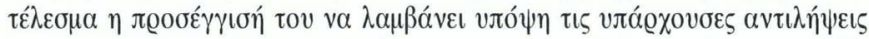

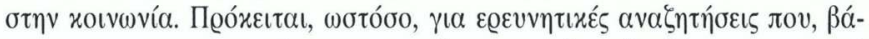

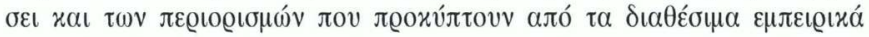

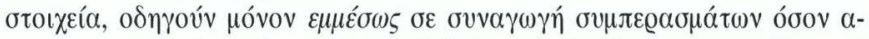

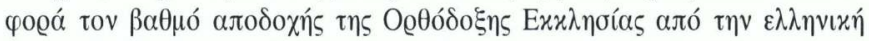

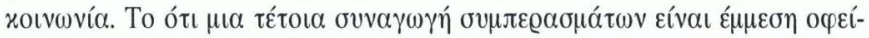

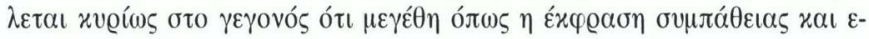

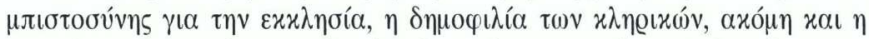

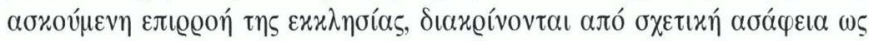

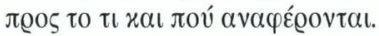

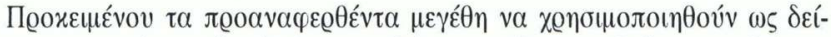

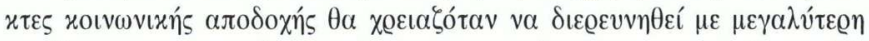

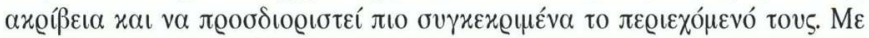

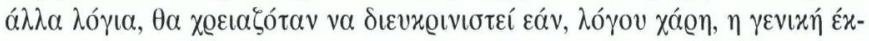

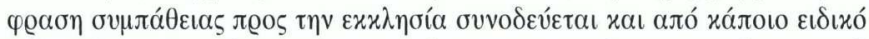

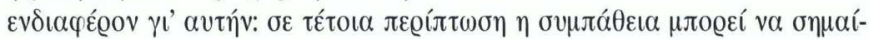

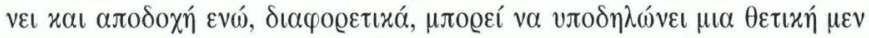

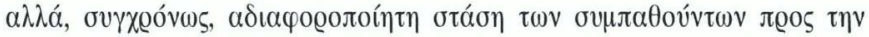

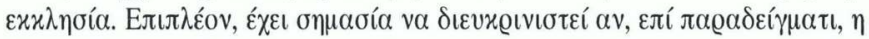

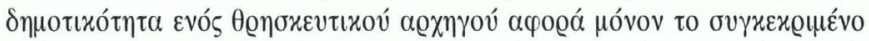

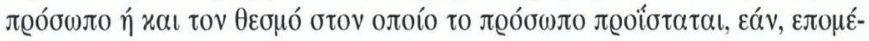

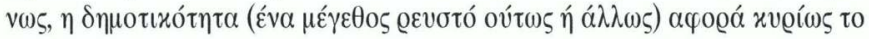

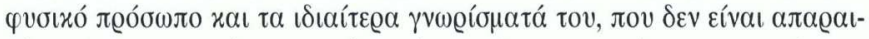

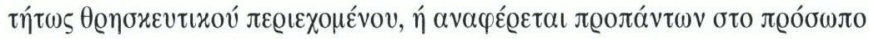




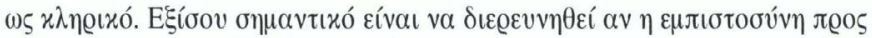

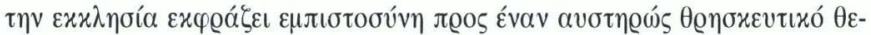

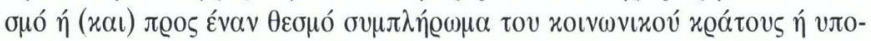

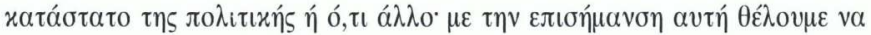

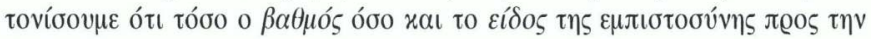

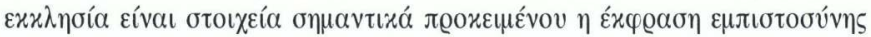

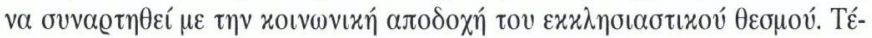

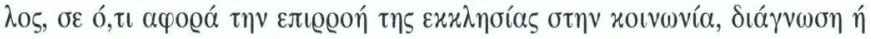

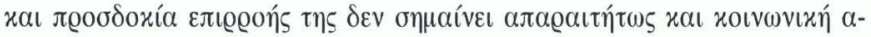

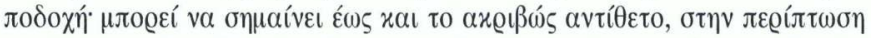

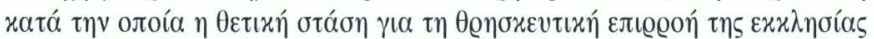

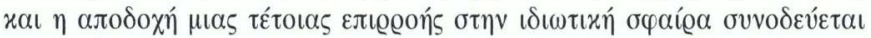

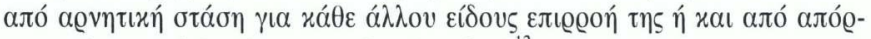

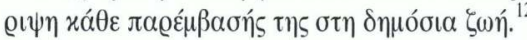

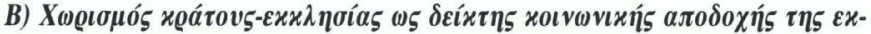

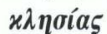

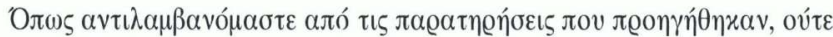

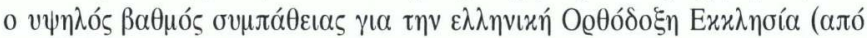

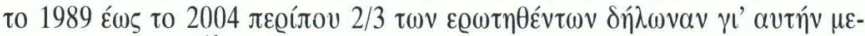

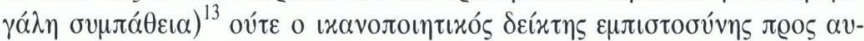

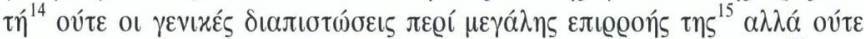

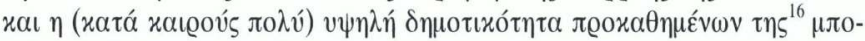

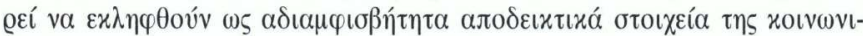

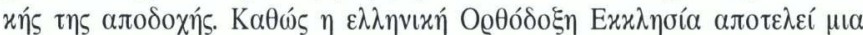

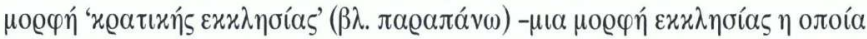

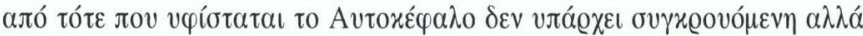

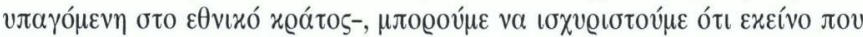

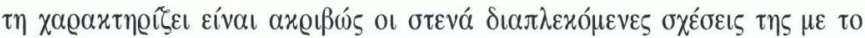

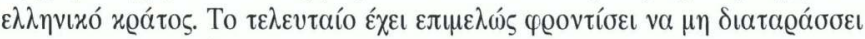

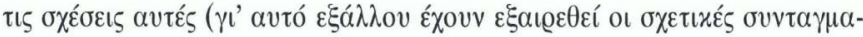

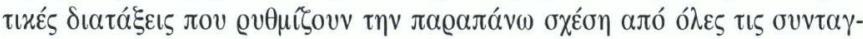
$\mu \alpha \tau$ น

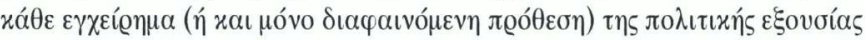

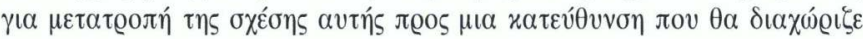




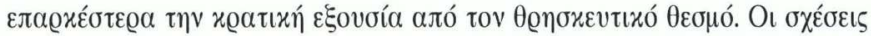

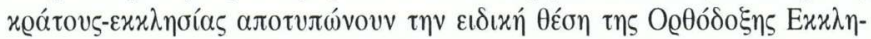

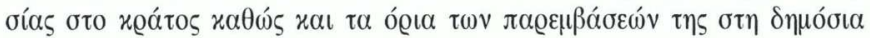

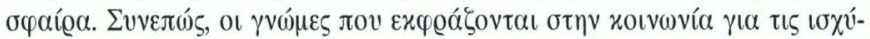

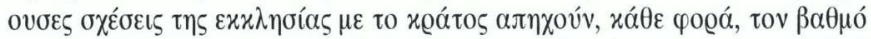

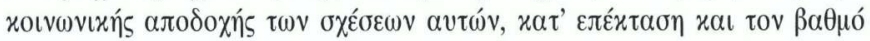

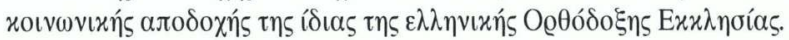

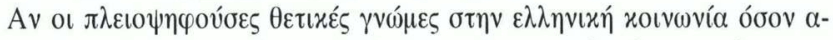

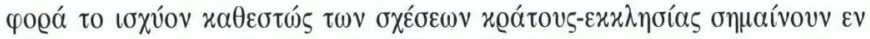

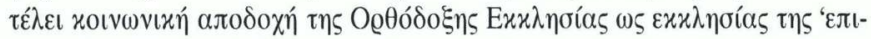

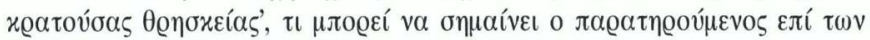

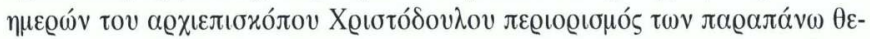

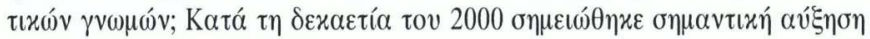

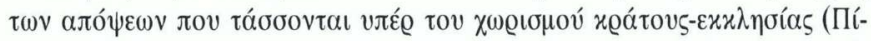

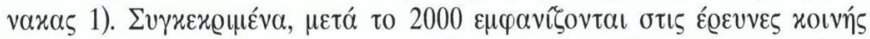

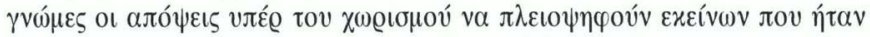

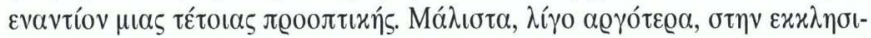

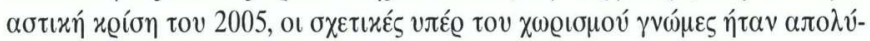

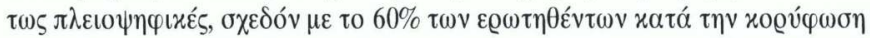

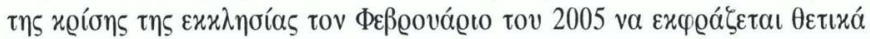

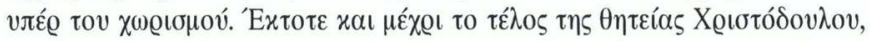

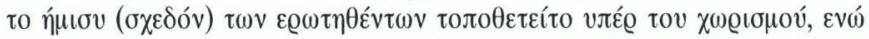

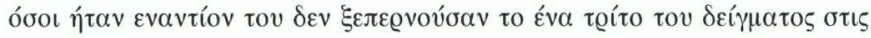

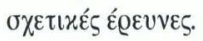

\section{IIivaxas 1.}

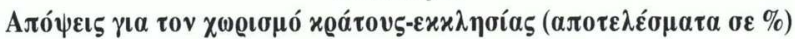

\begin{tabular}{|c|c|c|c|c|c|c|c|c|c|c|}
\hline & $\begin{array}{l}\text { Oxt. } \\
2000\end{array}$ & $\begin{array}{r}\text { Iov́d. } \\
2002\end{array}$ & $\begin{array}{c}\Phi \varepsilon \beta 0 . \\
2005\end{array}$ & $\begin{array}{l}\text { Ал } 0 . \\
2005\end{array}$ & $\begin{array}{l}\text { Ioúv. } \\
2005\end{array}$ & 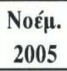 & $\begin{array}{l}\text { Máe. } \\
2006\end{array}$ & $\begin{array}{l}\text { Iov́v. } \\
2006\end{array}$ & $\begin{array}{l}\text { Máo. } \\
2007\end{array}$ & $\begin{array}{l}\text { Má@. } \\
2008\end{array}$ \\
\hline Үлє́ & 40,0 & 44,5 & 59,9 & 48,8 & 54,4 & 49,1 & 49,9 & 46,0 & $50 \%$ & 48,7 \\
\hline Kató & 50,8 & 38,4 & 24,0 & 33,8 & 28,1 & 32,5 & 32,4 & 30,5 & $28 \%$ & 34,4 \\
\hline
\end{tabular}

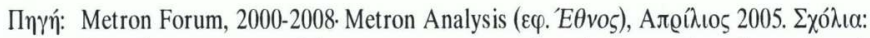

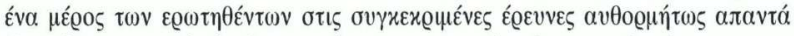

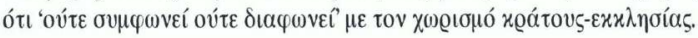




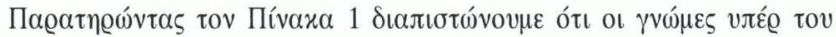

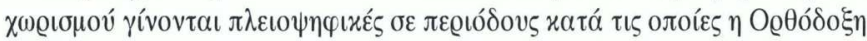

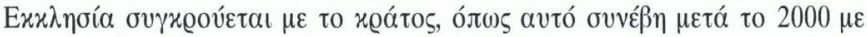

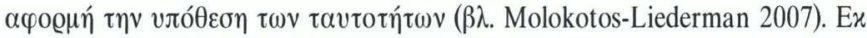

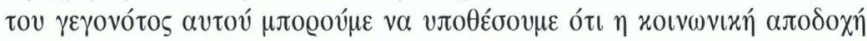

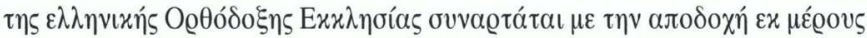

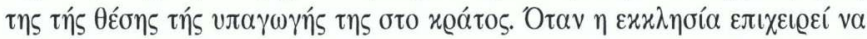

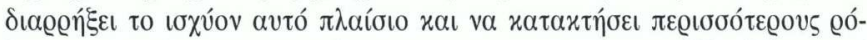

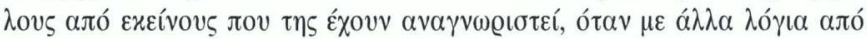

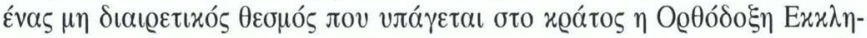

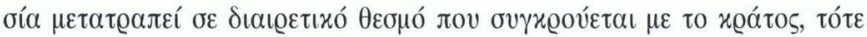

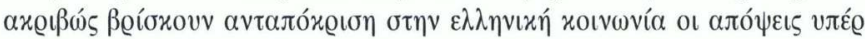

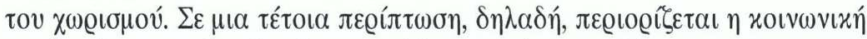

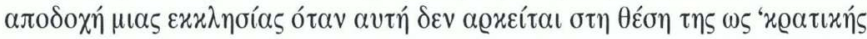

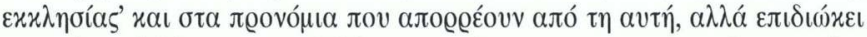

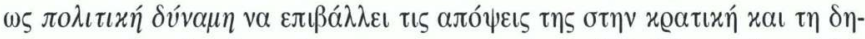

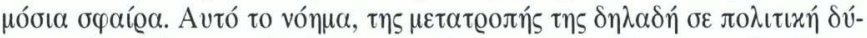

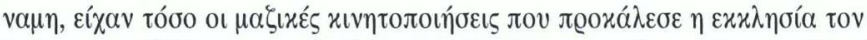

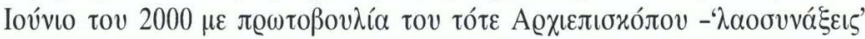

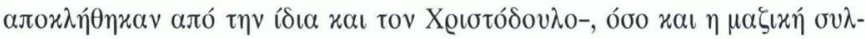

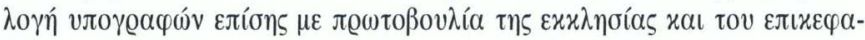

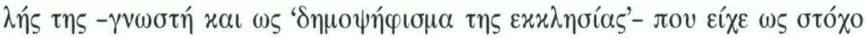

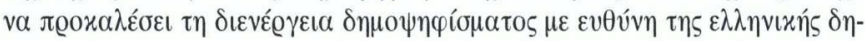

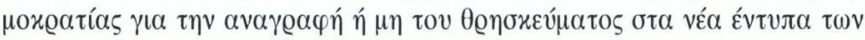

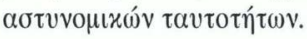

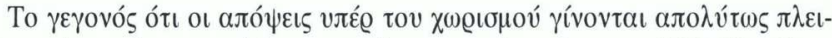

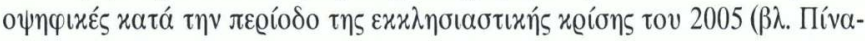

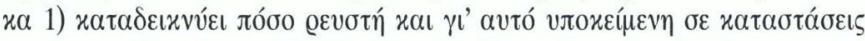

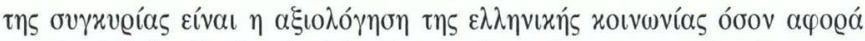

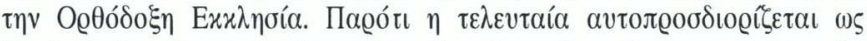

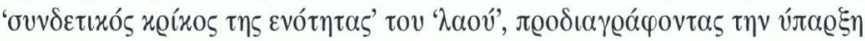

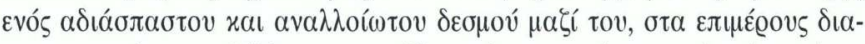

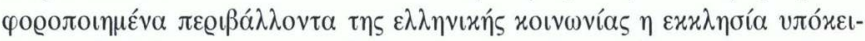

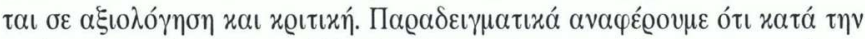

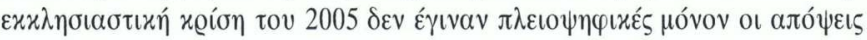




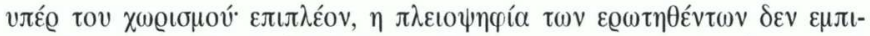

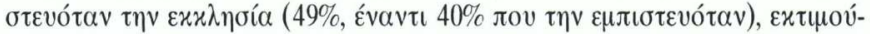

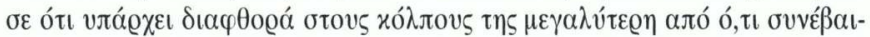

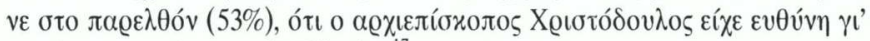

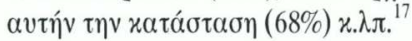

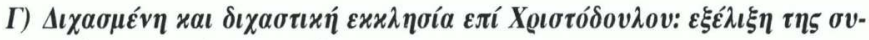

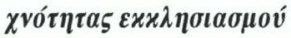

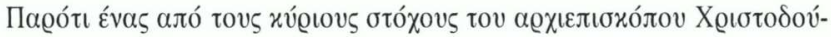

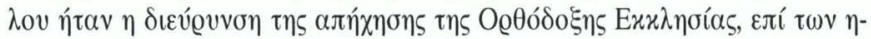

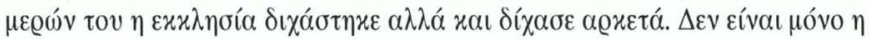

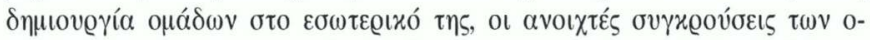

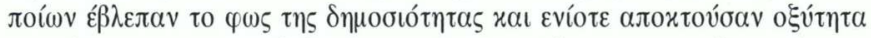

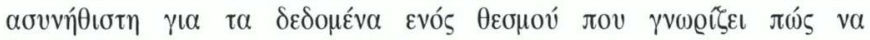

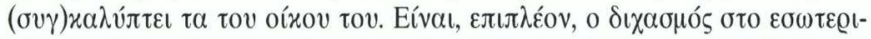

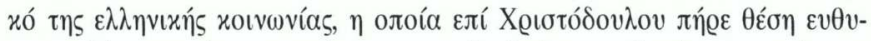

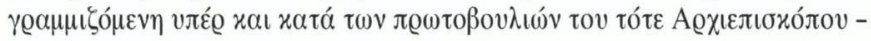

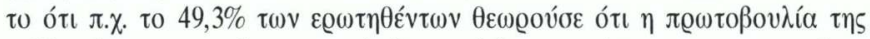

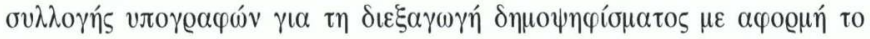

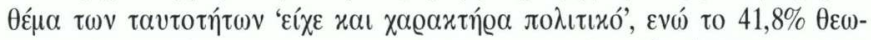

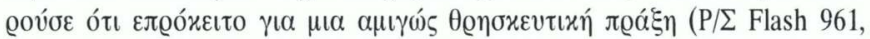

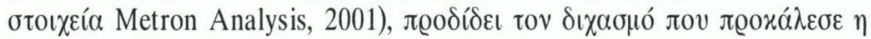

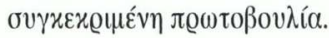

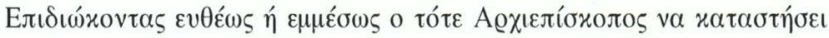

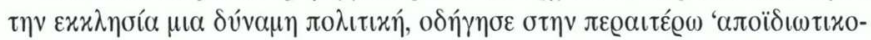

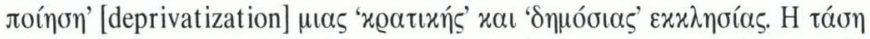

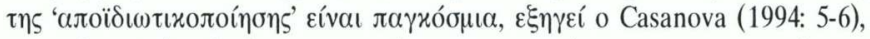

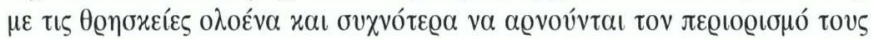

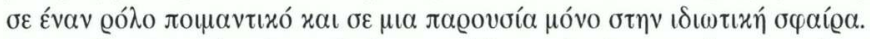

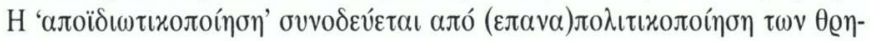

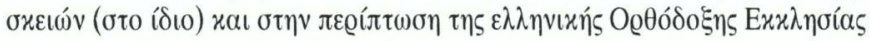

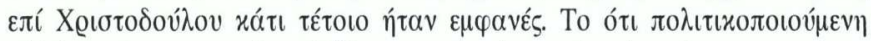

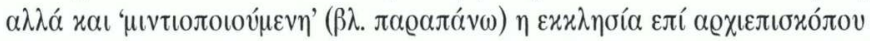

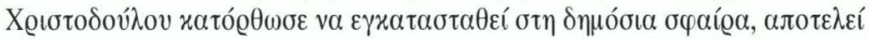

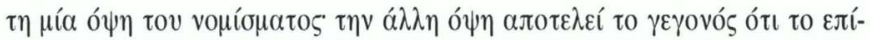




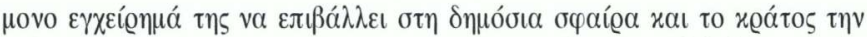

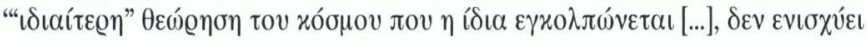

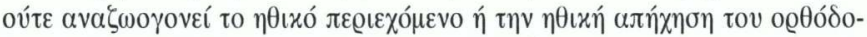

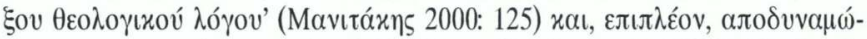

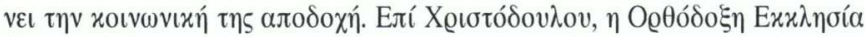

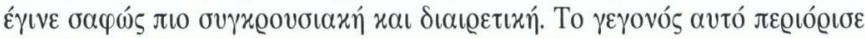

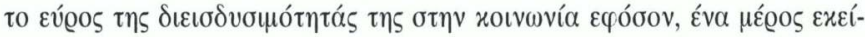

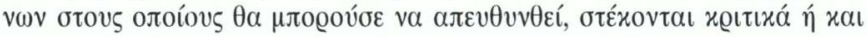

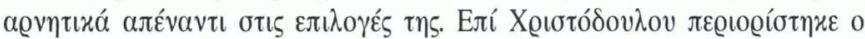

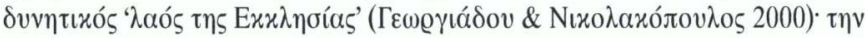

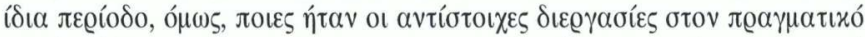

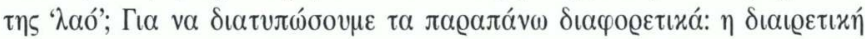

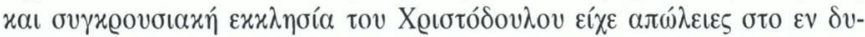

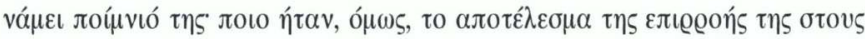

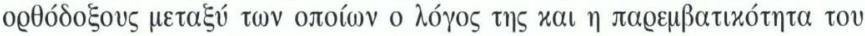

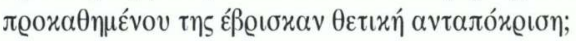

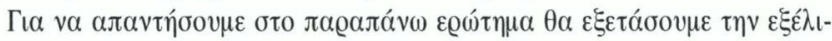

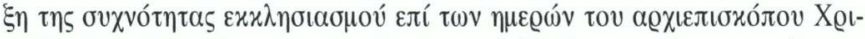

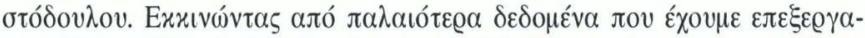

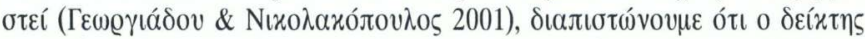

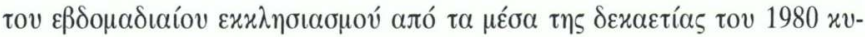

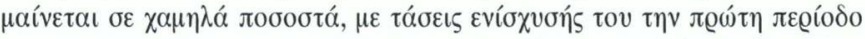

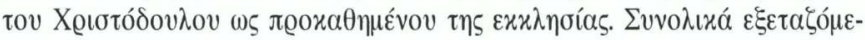

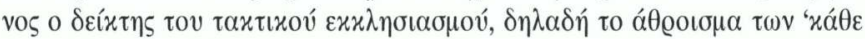

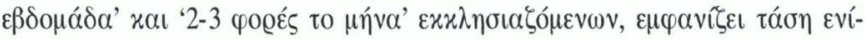

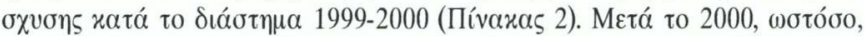

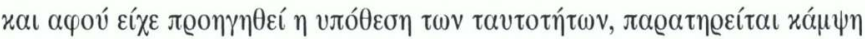

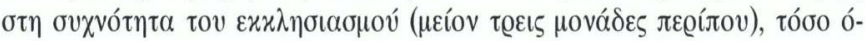

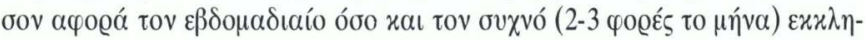

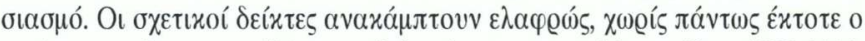

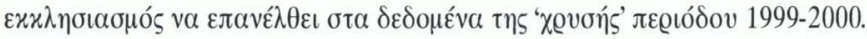

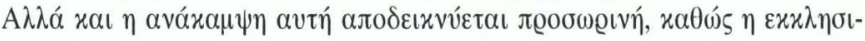

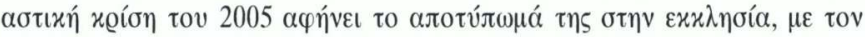

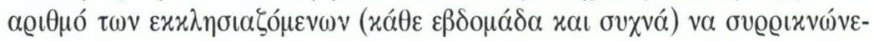

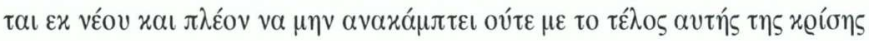




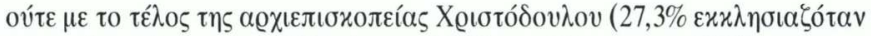

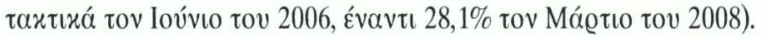

\section{Ilívaxas 2:}

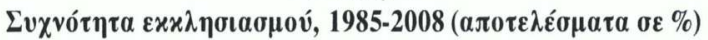

\begin{tabular}{|c|c|c|c|c|c|c|c|c|c|c|}
\hline & $\begin{array}{c}1985 \\
\text { EKKE }\end{array}$ & $\begin{array}{c}1993 \\
\text { Media } \\
\text { Plan }\end{array}$ & $\begin{array}{l}1995 \\
\text { MRB }\end{array}$ & $\begin{array}{r}1996 \\
\text { EKKE }\end{array}$ & $\begin{array}{l}1999 \\
\text { MRB }\end{array}$ & $\begin{array}{r}2000 \\
\text { VPRC }\end{array}$ & $\begin{array}{c}2002 \\
\text { Metron } \\
\text { Forum }\end{array}$ & $\begin{array}{r}2004 \\
\text { VPRC }\end{array}$ & $\begin{array}{c}2006 \\
\text { Metron }\end{array}$ & $\begin{array}{c}2008 \\
\text { Metron } \\
\text { Forum }\end{array}$ \\
\hline 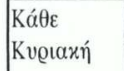 & 12,0 & 13,1 & 11,7 & 12,9 & 11,6 & 15,5 & 12,1 & 13,8 & 8,5 & 11,3 \\
\hline 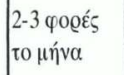 & 20,9 & 22,5 & 21,3 & 22,9 & 27,9 & 23,5 & 20,8 & 21,4 & 18,8 & 16,8 \\
\hline$\Sigma \pi 0 \varrho \alpha \delta ı x \alpha ́$ & 50,9 & 51,1 & 54,5 & 55,2 & 54,2 & 54,0 & 59,4 & 54,9 & 62,0 & 61,6 \\
\hline Потर́ & 16,1 & 13,2 & 12,3 & 8,8 & 5,8 & 5,0 & 6,9 & 8,3 & 9,2 & 8,6 \\
\hline
\end{tabular}

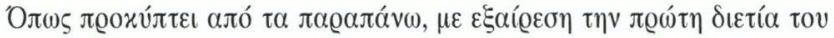

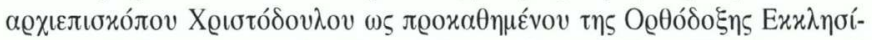

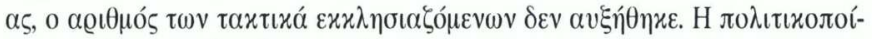

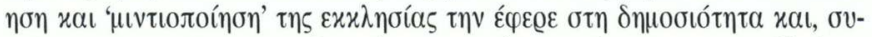

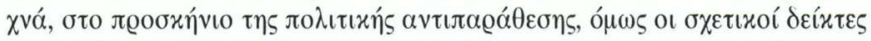

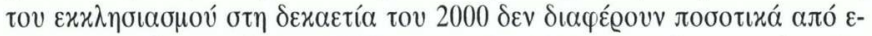

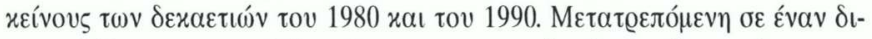

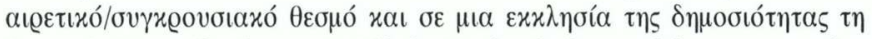

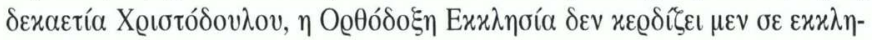

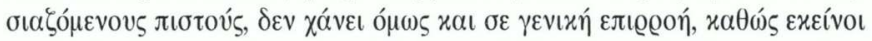

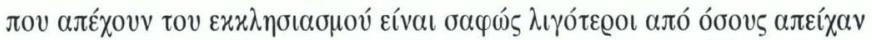

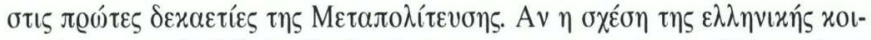

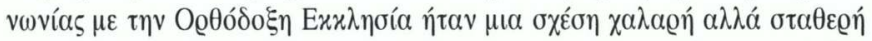

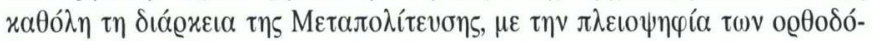

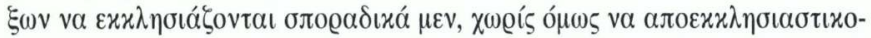

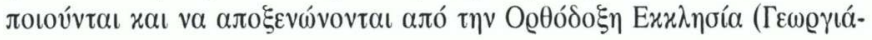




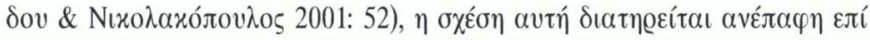

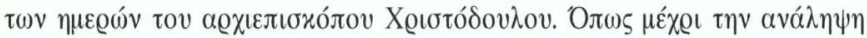

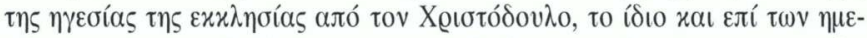

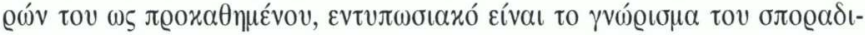

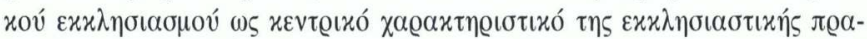

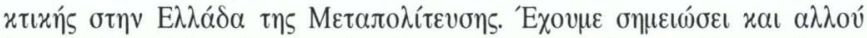

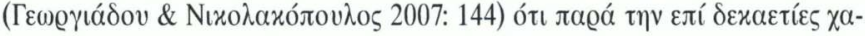

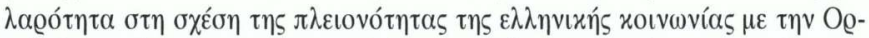

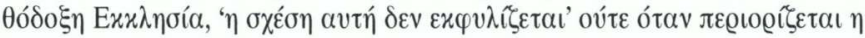

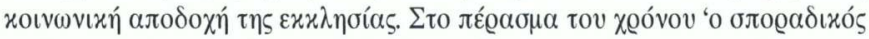

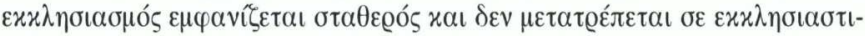

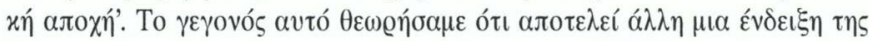

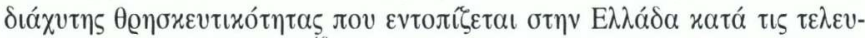

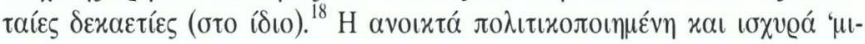

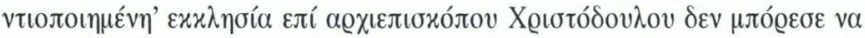

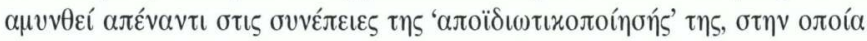

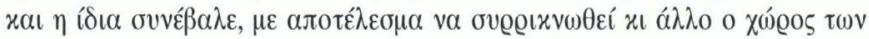

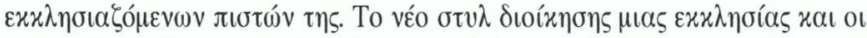

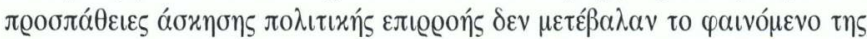

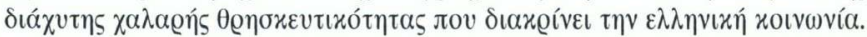

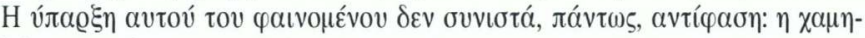

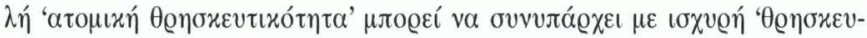

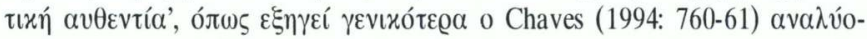

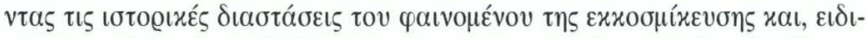

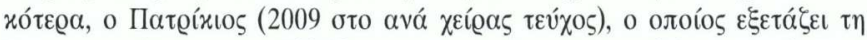

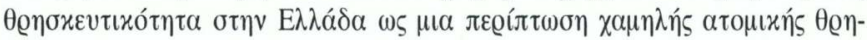

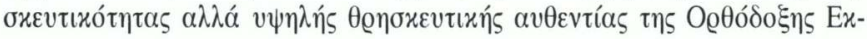

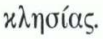

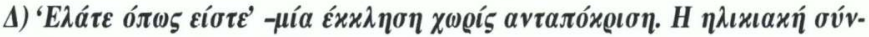 $\theta \varepsilon \sigma \eta \tau \omega v \varepsilon \varkappa x \lambda \eta \sigma \iota \alpha \zeta o ́ \mu \varepsilon v \omega v$}

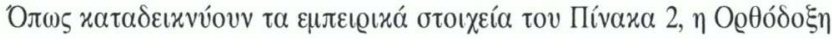

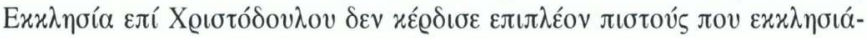

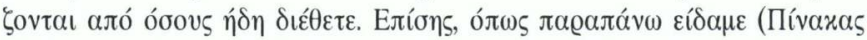

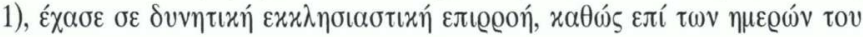




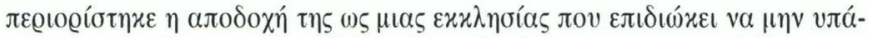

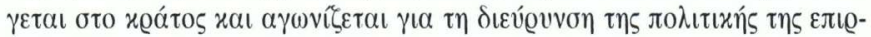

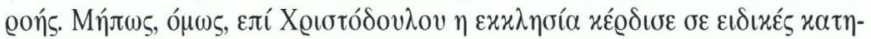

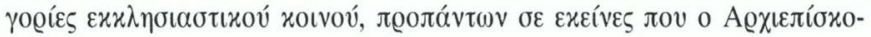

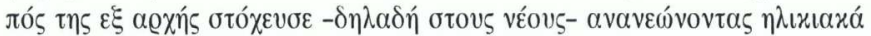

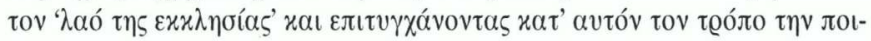

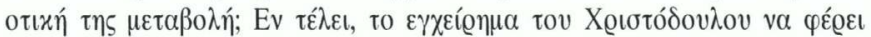

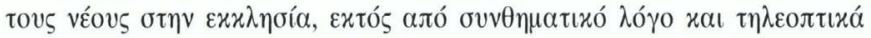

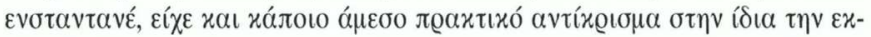

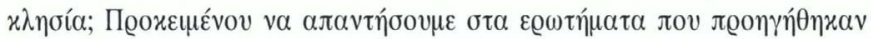

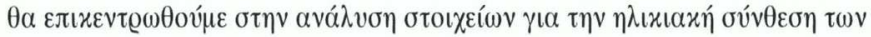

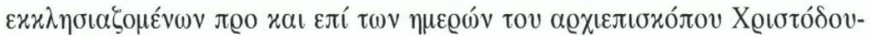

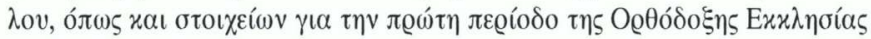

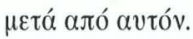

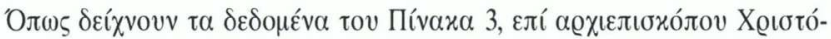

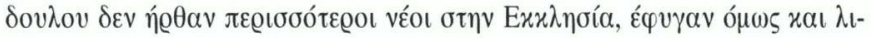

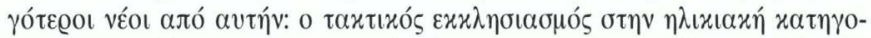

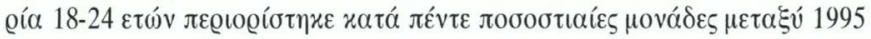

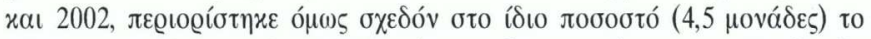

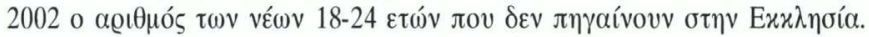

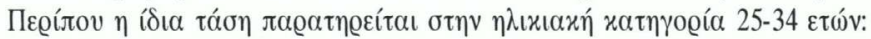

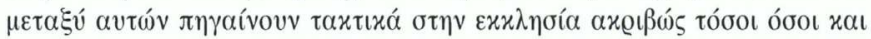

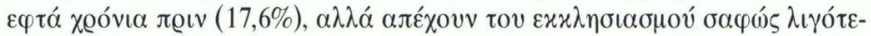

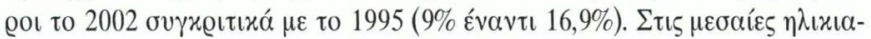

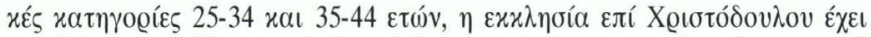

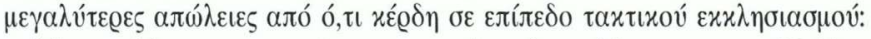

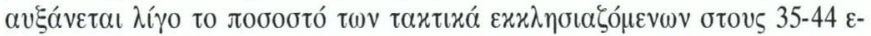

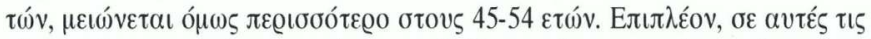

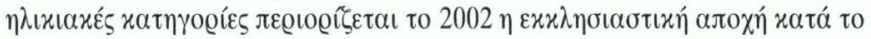

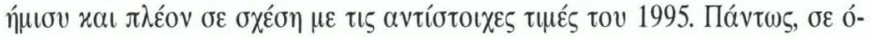

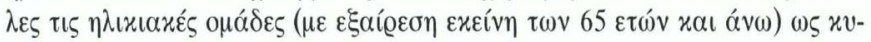

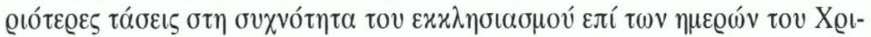

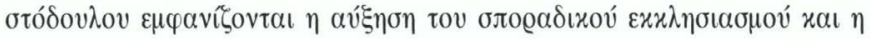

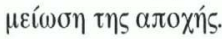




\section{Ilívaxas 3:}

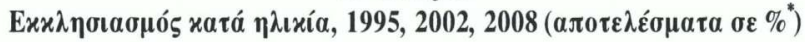

\begin{tabular}{|c|c|c|c|c|}
\hline 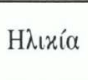 & 'Eтоక & 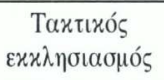 & $\begin{array}{c}\Sigma \pi 0 \varrho \alpha \delta เ x o ́ \varsigma \\
\varepsilon x \varkappa \lambda \eta \sigma เ \alpha \sigma \mu o ́ \varsigma\end{array}$ & Ало $\chi \eta^{* *}$ \\
\hline \multirow{3}{*}{$18-24$} & 1995 & 20,5 & 65,0 & 14,0 \\
\hline & 2002 & 15,6 & 72,9 & 10,5 \\
\hline & 2008 & 12,1 & 71,8 & 15,6 \\
\hline \multirow{3}{*}{$25-34$} & 1995 & 17,6 & 65,2 & 16,9 \\
\hline & 2002 & 17,6 & 72,4 & 9,0 \\
\hline & 2008 & 17,9 & 69,6 & 9,1 \\
\hline \multirow{3}{*}{$35-44$} & 1995 & 24,5 & 61,0 & 14,5 \\
\hline & 2002 & 26,3 & 66,2 & 6,7 \\
\hline & 2008 & 18,1 & 71,1 & 8,9 \\
\hline \multirow{3}{*}{$45-54$} & 1995 & 37,8 & 48,2 & 14,1 \\
\hline & 2002 & 31,8 & 58,3 & 7,2 \\
\hline & 2008 & 20,9 & 64,5 & 11,4 \\
\hline \multirow{3}{*}{$55-64$} & 1995 & 46,7 & 45,1 & 8,2 \\
\hline & 2002 & 39,5 & 55,4 & 6,0 \\
\hline & 2008 & 30,9 & 57,5 & 5,9 \\
\hline \multirow{3}{*}{$65+$} & 1995 & 56,2 & 39,0 & 4,3 \\
\hline & 2002 & 57,3 & 36,7 & 3,5 \\
\hline & 2008 & 54,3 & 41,4 & 3,6 \\
\hline
\end{tabular}

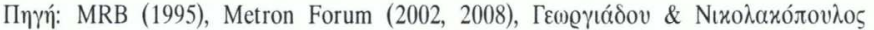

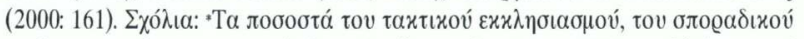

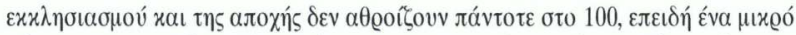

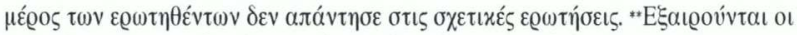

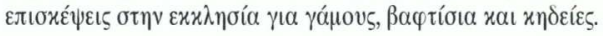

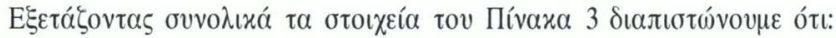

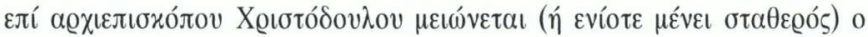

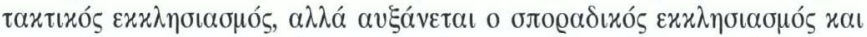

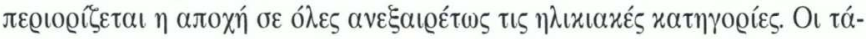




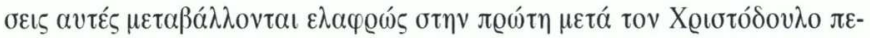

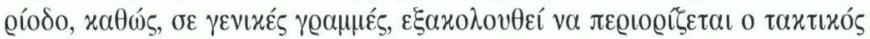

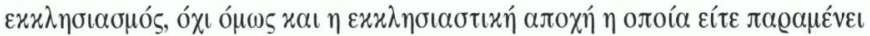

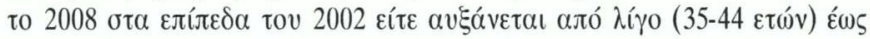

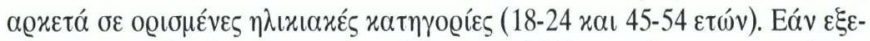

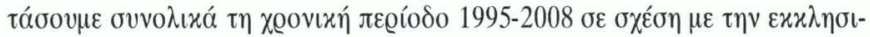

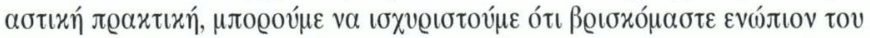

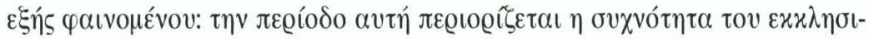

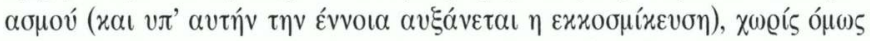

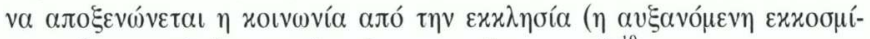

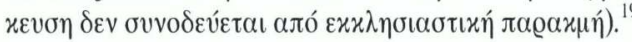

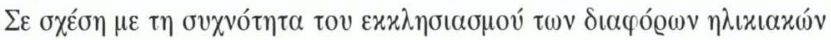

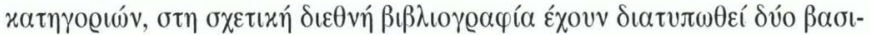

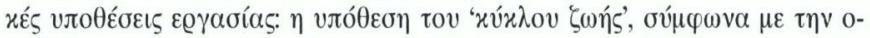

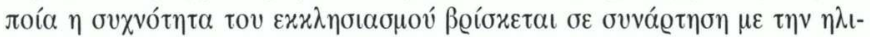

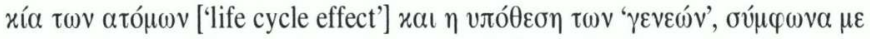

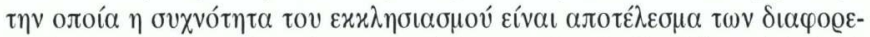

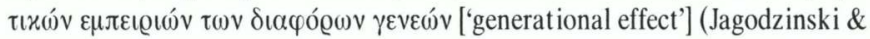

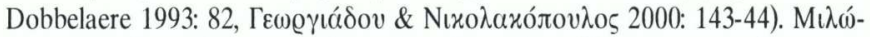

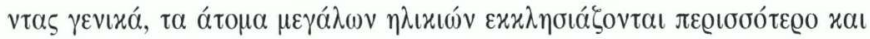

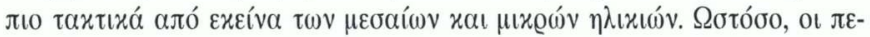

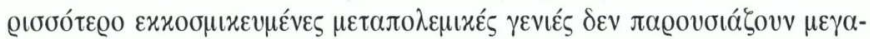

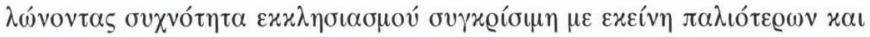

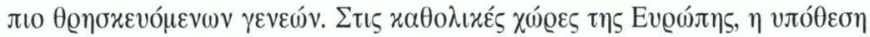

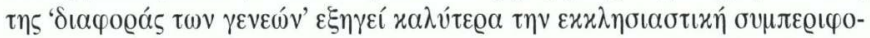

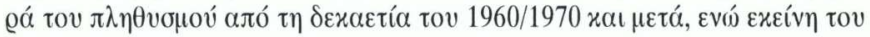

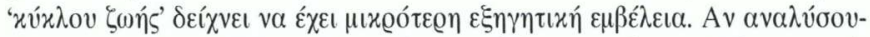

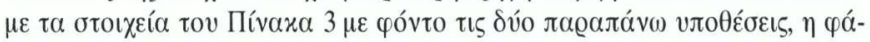

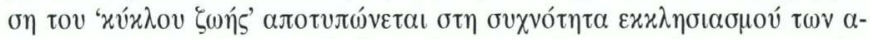

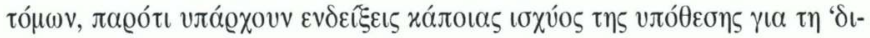

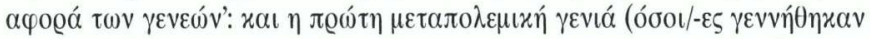

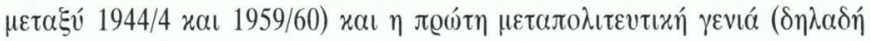

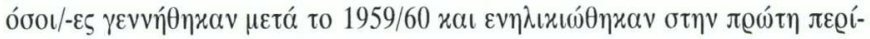

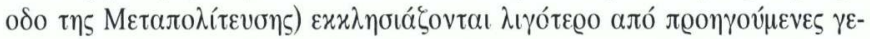

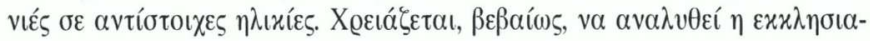




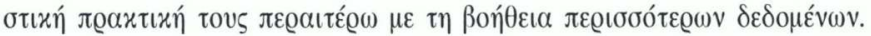

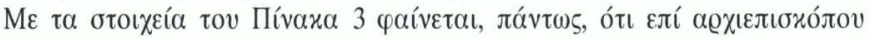

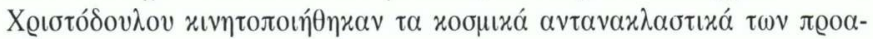

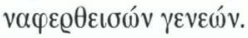

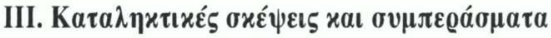

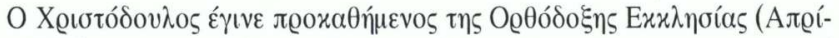

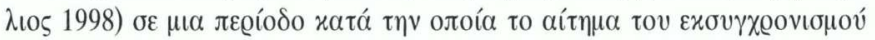

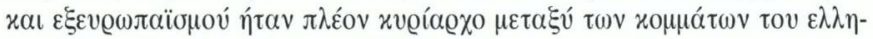

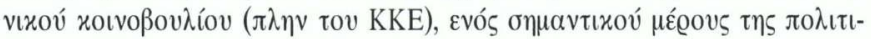

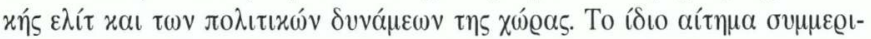

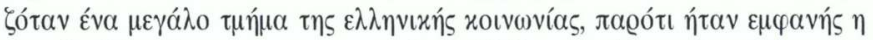

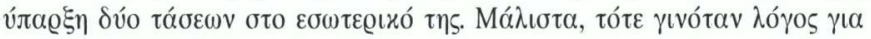

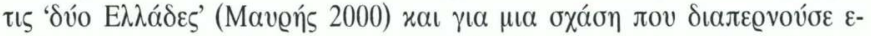

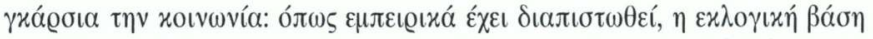

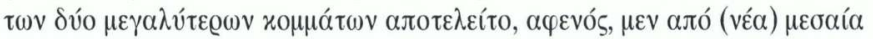

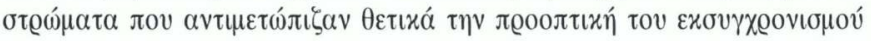

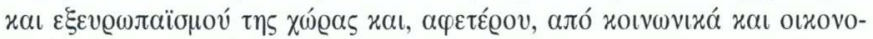

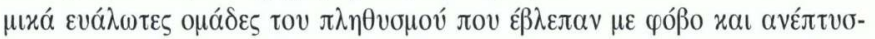

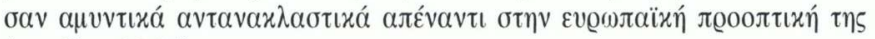
(бто í́ı: 22-24).

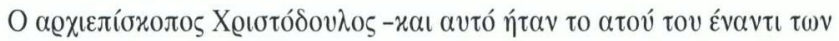

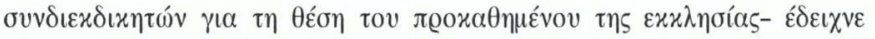

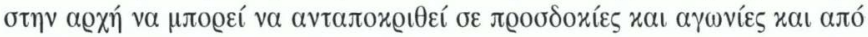

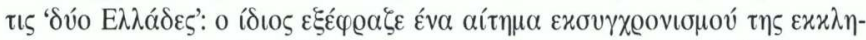

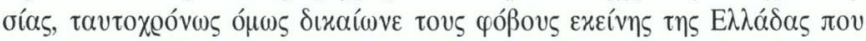
a

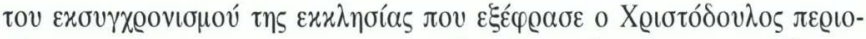

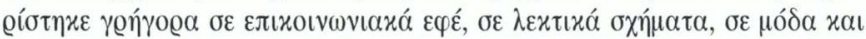

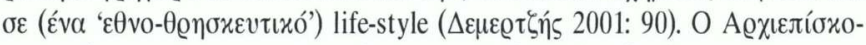

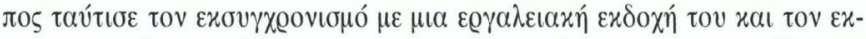

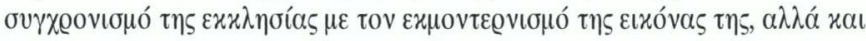

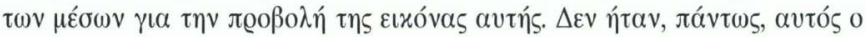

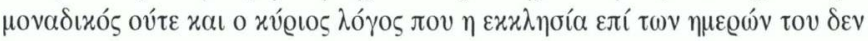




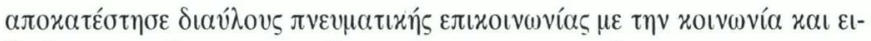

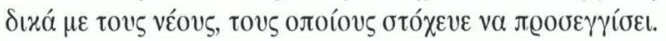

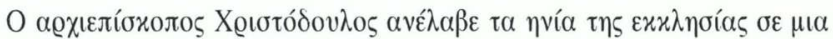

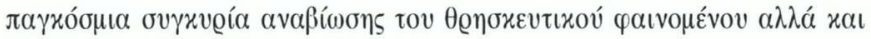

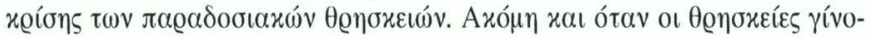

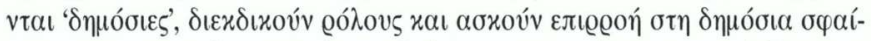

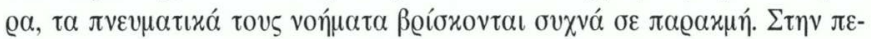

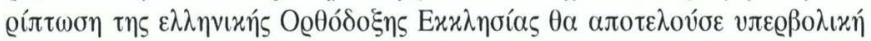

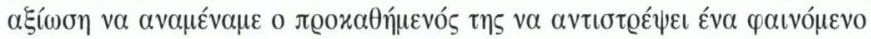

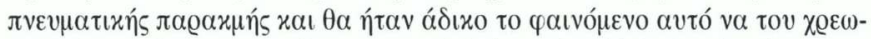

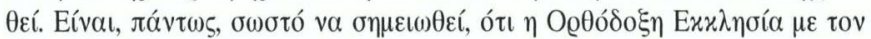

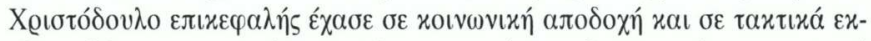

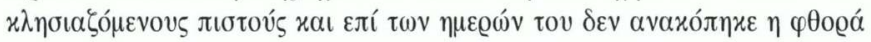

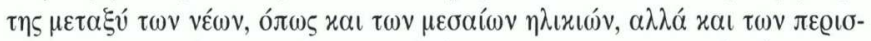

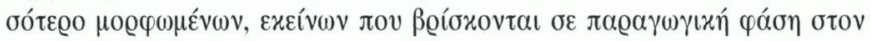

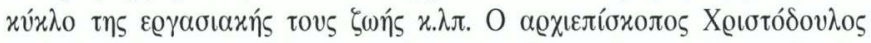

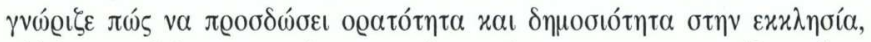

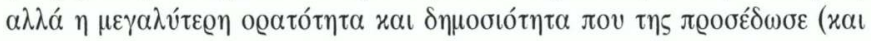

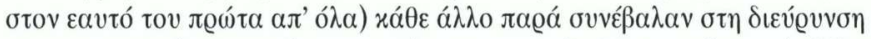

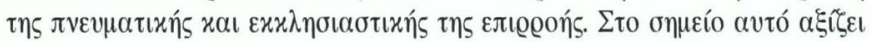

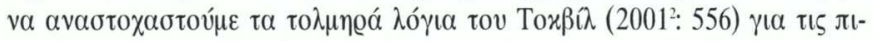

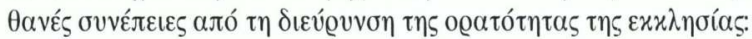

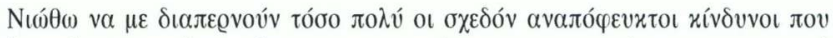

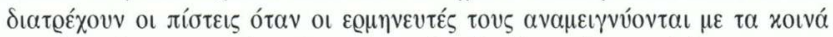

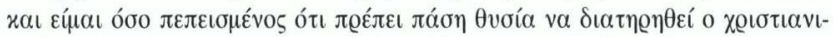
бцо́ร...,

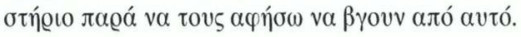

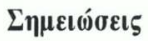

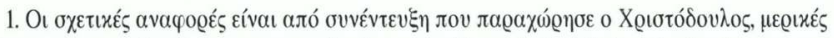

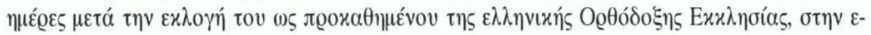

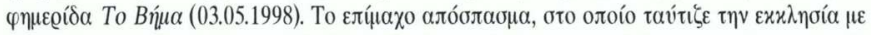

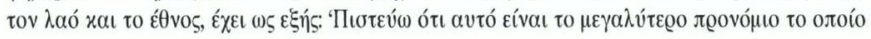




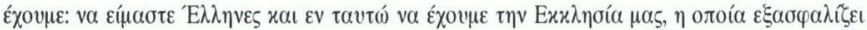

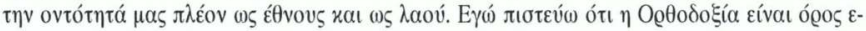

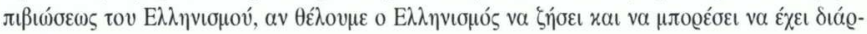
xદı'.

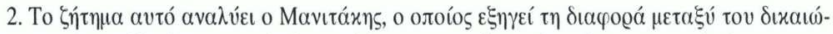

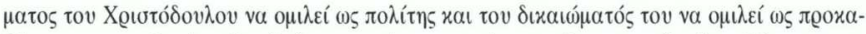

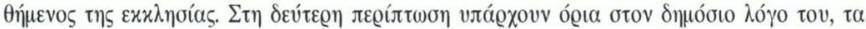

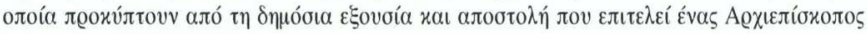
(Maviส́x

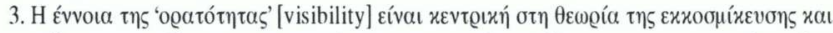

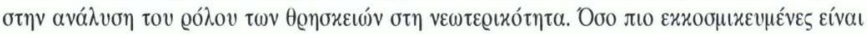

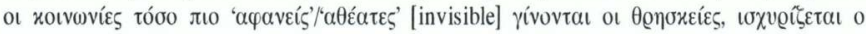

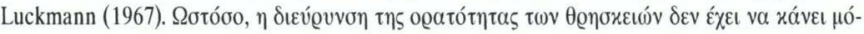

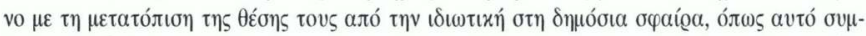

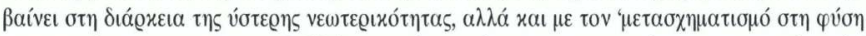

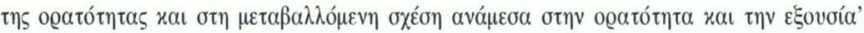

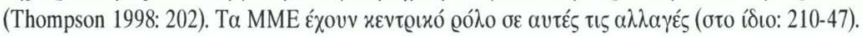

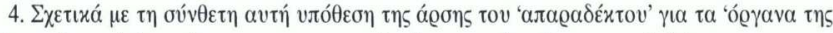

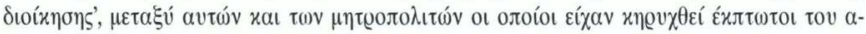

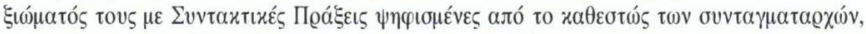

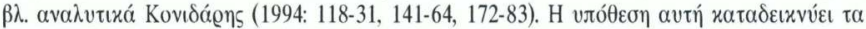

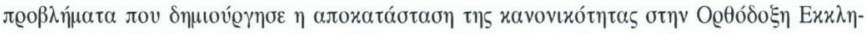

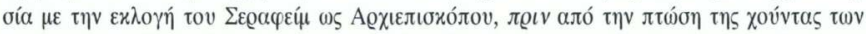

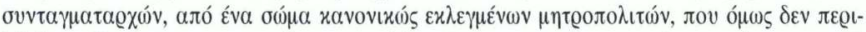

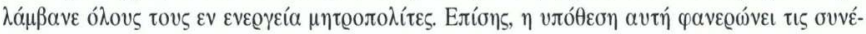

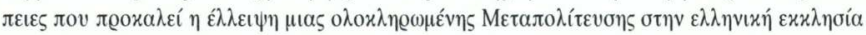

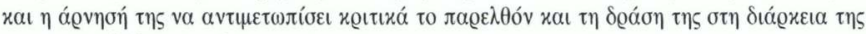

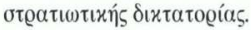

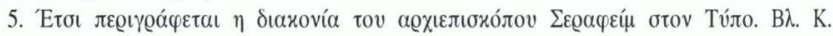

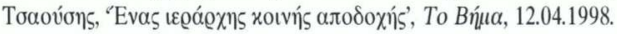

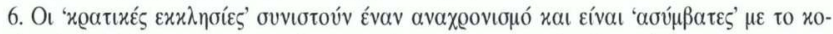

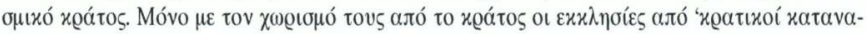

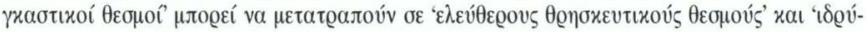

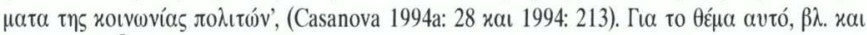

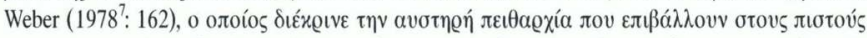

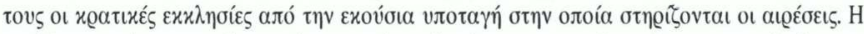

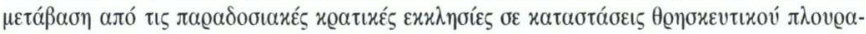

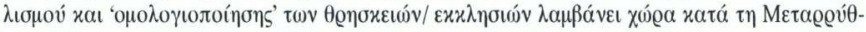

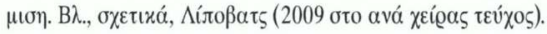




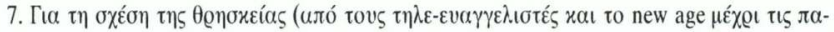

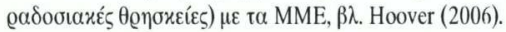

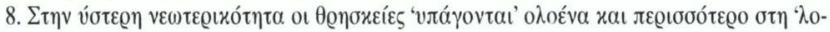

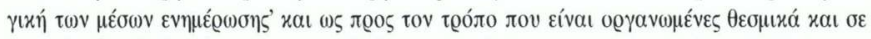

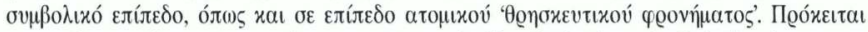

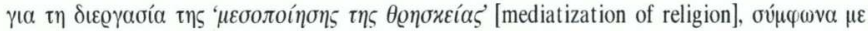

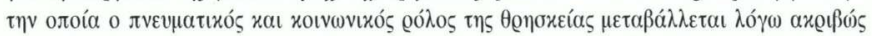

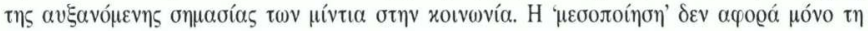

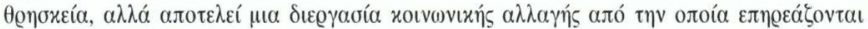

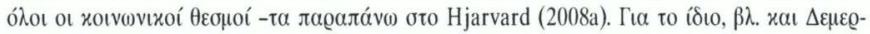

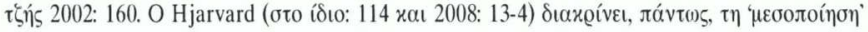

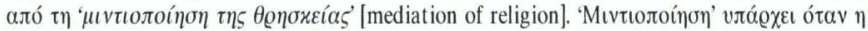

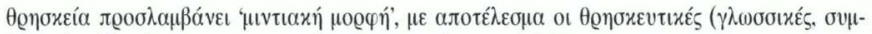

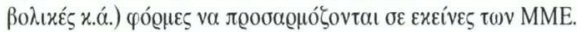

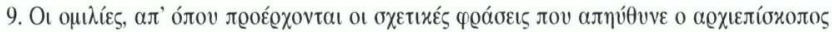

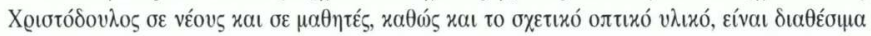

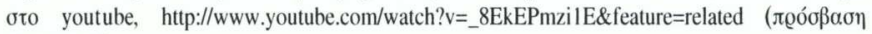
02.02.2009).

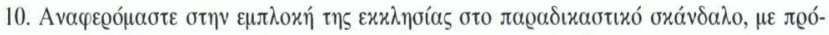

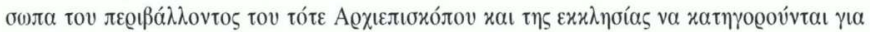

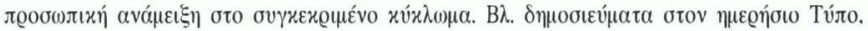

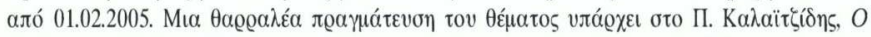

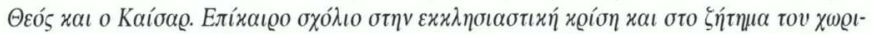

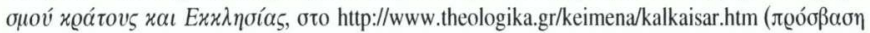
23.12.2008).

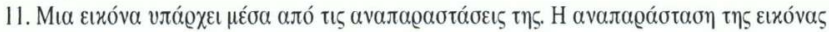

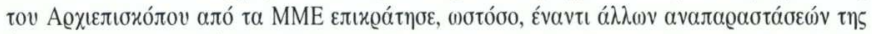

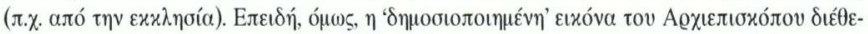

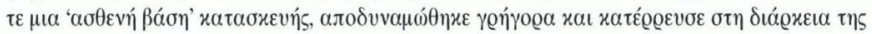

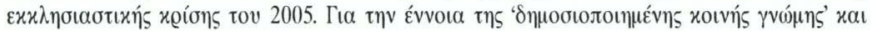

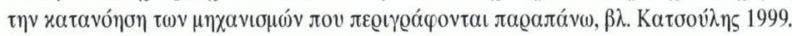

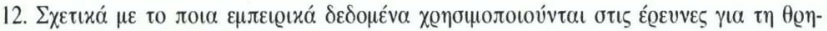

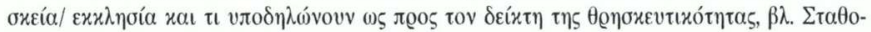
лoútov 2007.

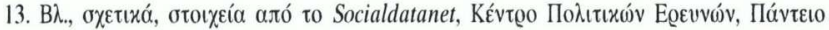

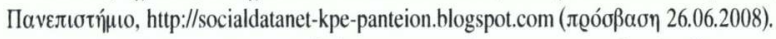

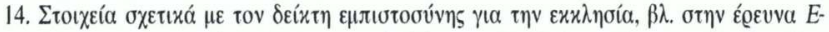

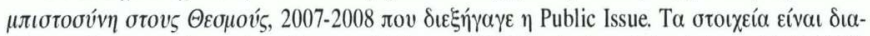

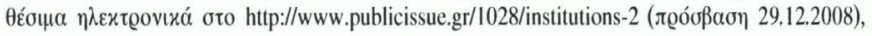




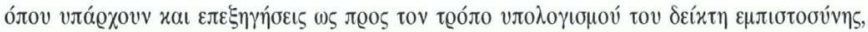

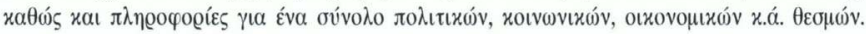

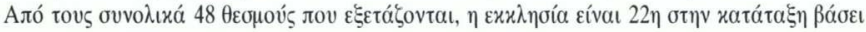

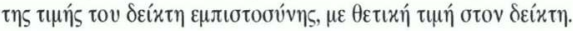

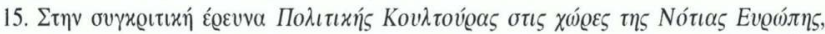

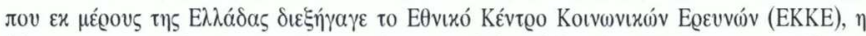

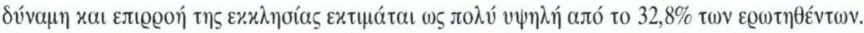

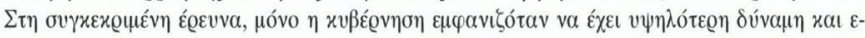

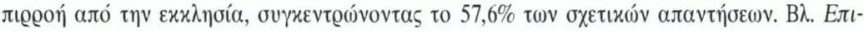

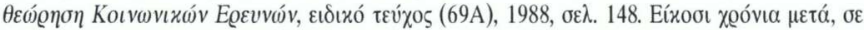

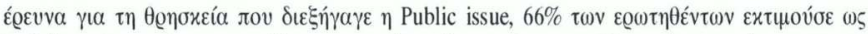

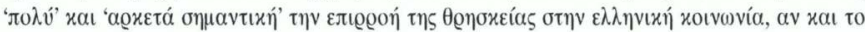

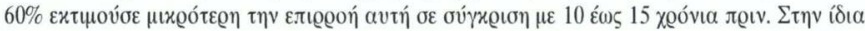

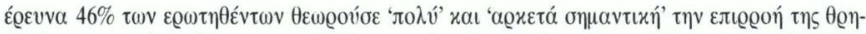

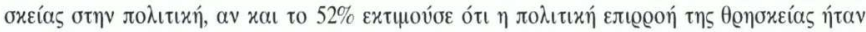

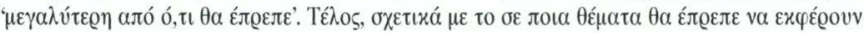

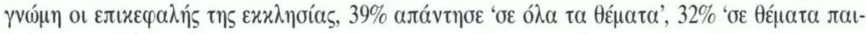

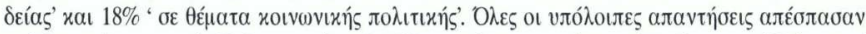

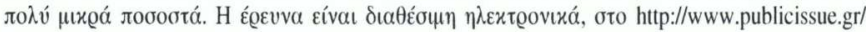

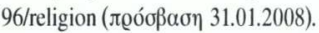

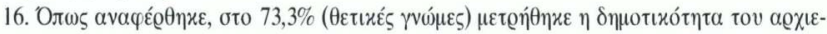

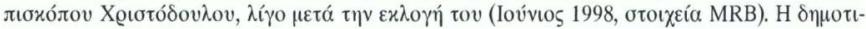

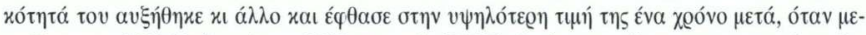

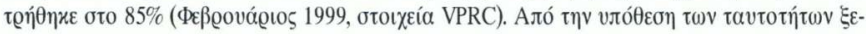

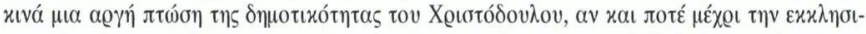

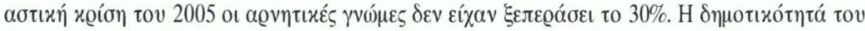

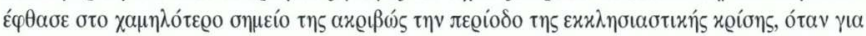

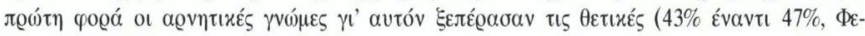

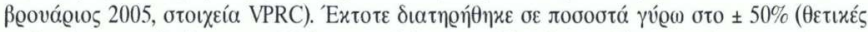

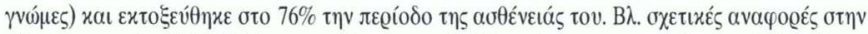

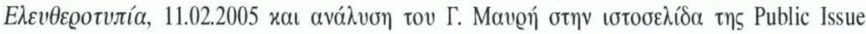

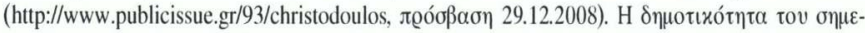

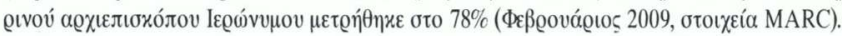

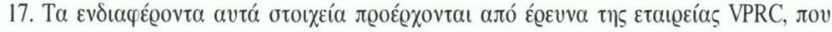

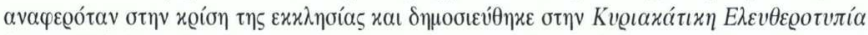

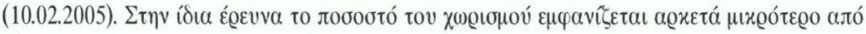

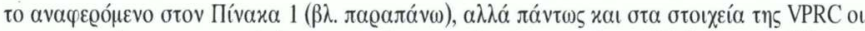

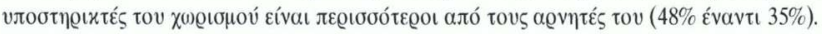




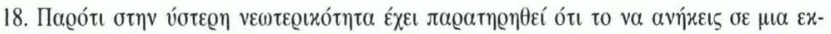

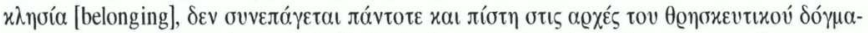

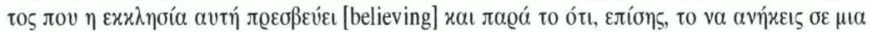

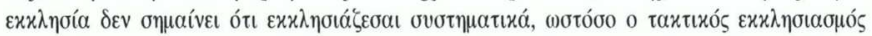

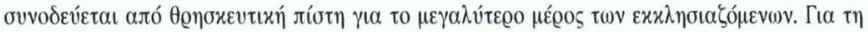

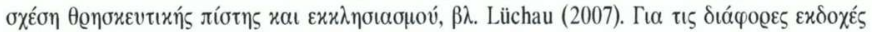

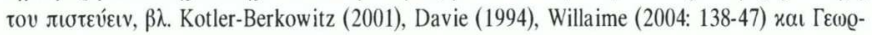

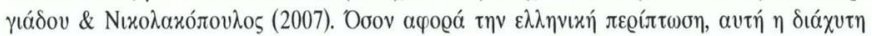

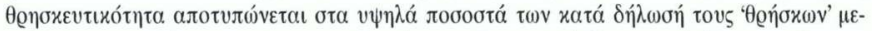

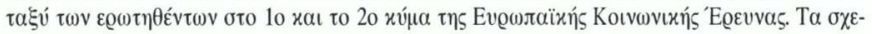

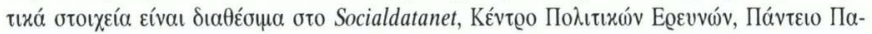

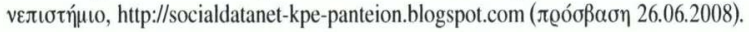

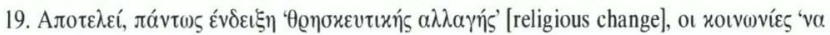

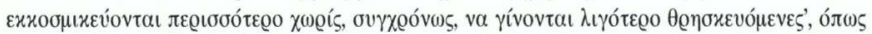

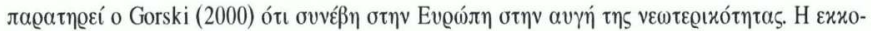

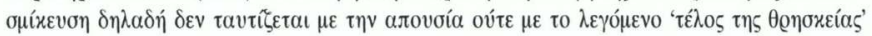

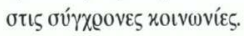

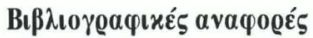

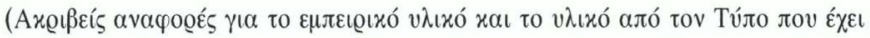

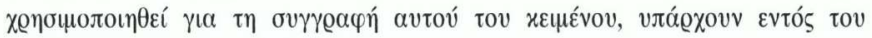

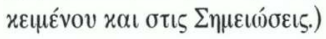

Alivizatos, N. (1999). 'A new role for the Greek Church?', Journal of Modern Greek Studies, 17.

Casanova, J. (1994). Public religions in the modern world, Chicago: University of Chicago Press.

Casanova, J. (1994a). 'Religion und Öffentlichkeit. Ein Ost-/Westvergleich', Transit, 8.

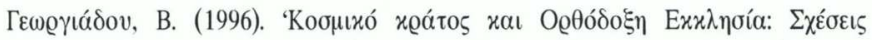

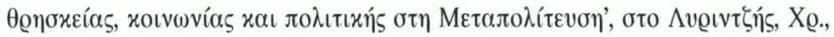

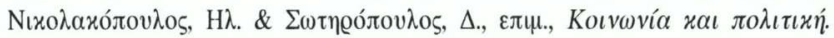

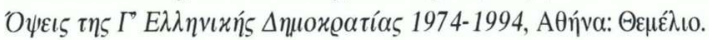

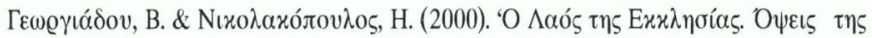

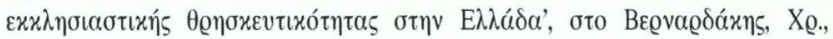

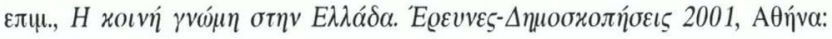

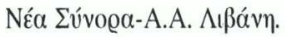




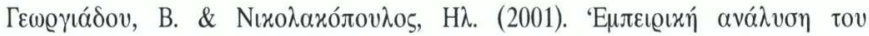

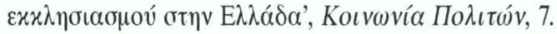

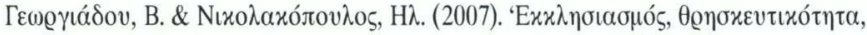

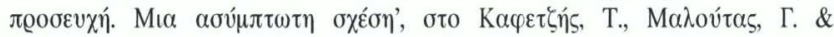

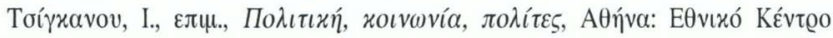

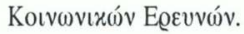

Chaves, M. (1994). 'Secularization as declining religious authority', Social Forces, 72(3).

Davie, G. (1994). Religion in Britain since 1945, Oxford: Blackwell.

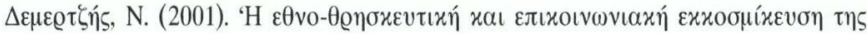

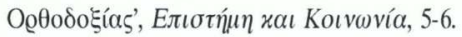

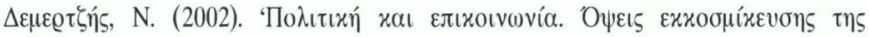

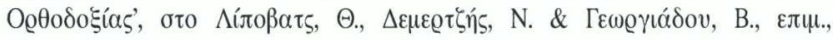

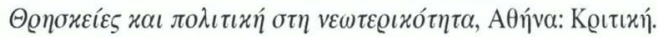

Gorski, Ph. (2000). 'Historicizing the secularization debate: Church, state, and society in late medieval and early modern Europe, ca. 1300 to 1700', American Sociological Review, 65(1).

Hjarvard, S. (2008). 'The mediatization of religion. A theory of the media as agents of religious change', Northern Lights, 6.

Hjarvard, S. (2008a). 'The mediatization of society. A theory of the media as agents of social and cultural change', Nordicom Review, 29(2).

Hoover, S. M. (2006). Religion in the media age, London \& New York: Routledge. Jagodzinski, W. \& Dobbelaere, K. (1993). 'Der Wandel kirchlicher Religiosität in

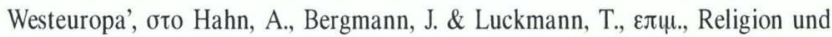

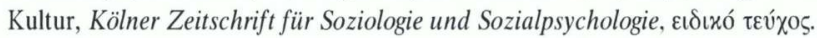

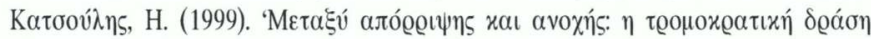

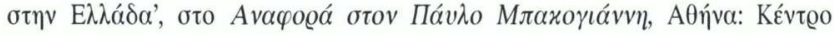

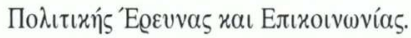

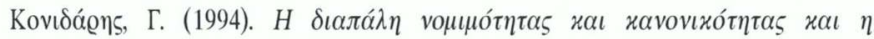

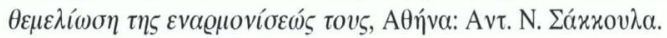

Kotler-Berkowitz, L. (2001). 'Religion and voting in Great Britain: A Reassessment', British Journal of Political Science, 31. 


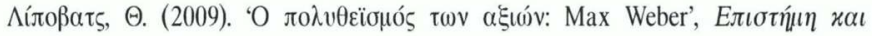
Koıv $\omega v i ́ \alpha, 21$.

Lüchau, P. (2007). 'By faith alone? Church attendance and Christian faith in three European countries', Journal of Contemporary Religion, 22(1).

Luckmann, Th. (1967). The invisible religion, New York: The Macmillan Company.

Makrides, V. (1991). 'Orthodoxy as a conditio sine qua non: Religion and state/politics in modern Greece from a socio-historical perspective', Ostkirchliche Studien, 40(4).

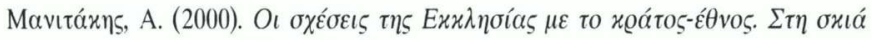

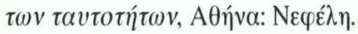

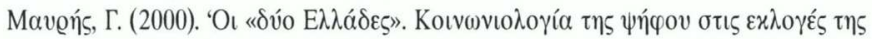

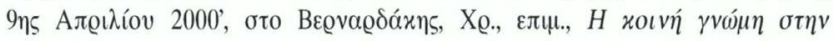

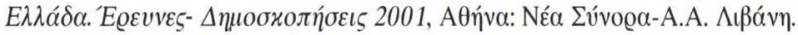

Molokotos-Liederman, L. (2007). 'The Greek ID card controversy: A case study of religion and national identity in a changing European Union', Journal of Contemporary Religion, 22(1).

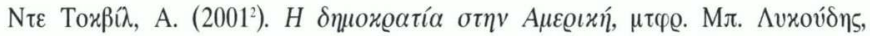

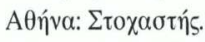

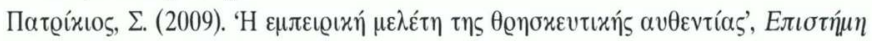

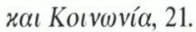

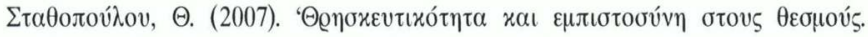

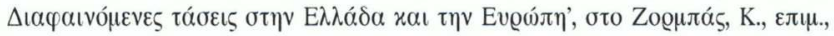

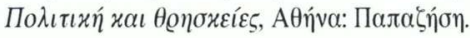

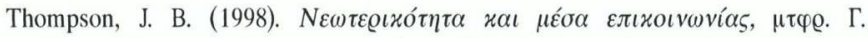

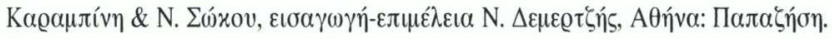

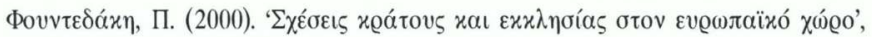
To $\Sigma v ́ v \tau \alpha \gamma \mu \alpha, 26(4-5)$.

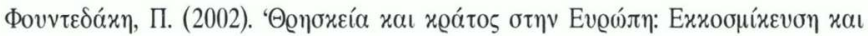

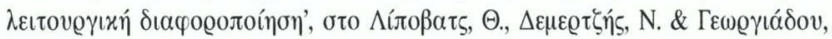

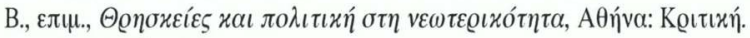

Weber, M. (19787). Gesammelte Aufsätze zur Religionssoziologie, 1. тó gen: J. C. B. Mohr (Paul Siebeck). 


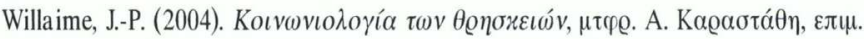

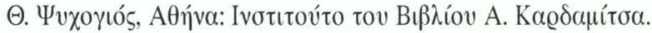

